\title{
STUDIES ON INDIAN COPEPODS 5. ON ELEVEN NEW SPECIES OF MARINE CYCLOPOID COPEPODS FROM THE SOUTH-EAST COAST OF INDIA*
}

\author{
By A. N. P. UMmerkuTTY \\ Central Marine Fisheries Research Institute, Mandapam Camp
}

\section{INTRODUCTION}

SEwELL (1949) has pointed out that our knowledge of the cyclopoid copepods of Indian waters, especially those inhabiting the littoral regions in association with invertebrates and sea weeds and in which the type of existence is usually referred to as 'semi-parasitic', is extremely scanty. The oldest account available on this little known crustacean group in our waters is that of Thompson \& Scott (1903) who, in their supplementary reports of the faunistic survey of the Pearl Banks of Ceylon, gave brief description of the copepods they came across. The cyclopoid copepods they dealt with were mostly obtained by examination of washings from dredged materials such as ascidians, sponges, corals, pearl oysters etc. Although the exact depth at which they were caught is not given in specific instances it is presumably from sea bottoms, at least a few fathoms deep. "This collection of copepods have proved to be exceedingly rich and varied, containing as it does, no less than 283 species, of which 76 are new to science while at least 10 new genera ate required' (Thomp. \& Scott, loc. cit.). Of these copepods, the 'semi-parasitic' cyclopoids were one of the richest groups; it was represented by 42 species of which 25 were new and no less than six new genera were required to accommodate eight of the new species. The only other exhaustive work on these tiny creatures in the Indian waters is that of Sewell (loc. cit.) who described the species obtained during the John Murray Expedition and also those he gathered during the long years of his valuable service in this country in the Marine Survey of India. He recorded 44 species belonging to this group, out of which 25 were new and 3 new genera and 2 sub-genera, had to be created to include some of the new species. Krishnaswamy (1954) recently reported three species from Madras coast ; all the three are new to our waters and one of them is new to science. Attention may be drawn here to the 2 new genera of cyclopoid copepods that have recently been reported from this area (Ummerkutty, 1960a and 1960b).

* Published with the permission of the Director, Central Marine Fisheries Research Institute. 
The present paper deals with the following new species of copepods :-

(1) Asteropontius littoralis

(2) A. sewelli

(3) Cryptopontius graciloides

(4) C.orientalis

(5) Hemicyclops intermedius

(6) Pseudoanthessius agilis

(7) Macrochiron (Macrochiron) rigida

(8) Lichomolgus holothuriae

(9) L. serratipes

(10) L. brevifurcatus

and (11) L. indicus.

It is of interest to note that many of the copepods recorded or discovered from the Ceylon Pearl Oyster Grounds by Thompson \& Scott about 60 years back have now been obtained by me from the Indian side of the Gulf of Mannar. A detailed account of these species will be published elsewhere.

Gooding (1957) has pointed out the undesirability of referring these animals collectively under such terms as "parasitic', 'semi-parasitic', 'commensal' etc., for there is little definite evidence about the nature of the association and little work to this end has been done on the copepods. Sars (1918) who first referred to their parasitic existence has qualified his statement by adding that 'in most cases, however, the parasitism may be merely temporary'. The fact is that most of the species are found to occur in association with a variety of hosis and the exact relationship between the copepod and the associated invertebrate is yet to be investigated in specific cases. Because of this ambiguity in their relationships I have preferred to refer to them as "associated with invertebrates' instead of referring them as parasitic or semi-parasitic. In the present collection only Lichomolgus holothuriae was found constantly to live inside the body cavity of Holothuria sp. Although there is no positive evidence that it is not found in association with other invertebrates, quite a number of holothurians examined yielded this copepod. P. serratipes was obtained from the washings of Pteroeides esperi Herklots, the common sea-pen of this coast. Asteropontius littoralis was obtained mostly from washings of weeds and mud-covered coral stones. Whether it has any relation with the Polychaetes observed to inhabit the same niche is not clear. Of the species discussed below, the following are represented by both the sexes.

(1) Cryptopontius orientalis

(2) Pseudoanthessius agilis

(3) Macrochiron (Macrochiron) rigida

(4) Lichomolgus holothuriae

(5) L. brevifurcatus

and (6) L. indicus

In describing the various body segments I have mainly adopted the terminology suggested by Gooding (loc. cit.) wilh some alterations (Ummerkutty, 1960 a \& b). 
In the section Siphonostoma all the cephalosomal appendages are easily distinguishable; but in the section Poecilostoma there is a reduction in the mouth-parts and the homology of the various appendages has been a source of discussion among the carcinologists. Brady (1880) considered that the mandible, the maxillule (first maxilla), the maxilla and the maxilliped are present ; and this view has been shared by great many of the subsequent workers. [Gurney, 1927; Nicholls, 1944 ; Sewell (loc. cit.) and Gooding (loc, cit.) ] However, Sars (loc. cit.) held a different view. He maintained that the mandible is absent in all the Poecilostoma and what is usually described as mandible is nothing but 'a part of the foremost pair having been erroneously taken for an independent limb'. At least as far as the family Clausidiidae is concerned Nicholls (loc. cit.) has shown beyond doubt that there are four pairs of oral appendages present: "The few specimens of Hemicyclops found in this collection have been dissected with particular attention as to whether these two anterior pairs of mouth-parts came away together or were attached separately. In each case I found no attachment between them and during dissection observed that they were independently mounted side by side on the supporting skeleton. I am, therefore, convinced that there are two separate appendages: the mandible, which has the typical shape of such an appendage though lacking a palp and having a somewhat specialized armature and the maxillule, which is here distinctly cleft, the smaller lobe armed with strong spines representing the gnathobase, the larger lobe with setae only being the palp' (p. 44). Gurney (loc, cit.) goes further and states that even in Lichomolgidae, the mandible and its 'palp' are separable and can be recognized as distinct appendages.

As to the oral appendages of lichomolgids that are dealt with in this paper it is clear that all the four pairs are present, although highly reduced in some cases. In all cases, however, the mandible and the maxillule are very closely set. The drawings of these appendages have been made together. In describing the various appendages I have confined to the usage of those terms which are currently in vogue among the copepodologists. The terms protopod, exopod and endopod are used to indicate the basal, the external and the internal components respectively. These terms have been employed to describe not only the swimming legs but also the cephalosomal appendages.

\section{Material and Methods}

The material of the present study was obtained from the Gulf of Mannar and the Palk Bay on the south-east coast of India off Mandapam. Some of the species were found to occur in both the areas. Others were caught only in one of the two seas. All the collections were made in the inshore waters with a maximum depth of two meters and the period of collections was spread over from May to August 1960. The following method was adopted for the collection: Weeds, mud-covered coral stone, sponges, holothurians, starfishes etc. etc., were vigorously washed separately into hand-nets made of organdie cloth. Smaller mud particles were sifted out by repeated dipping of the net into sea water. The remaining portion was transferred to large glass jars and preserved in formalin. Larger non-copepod items were later hand-picked and discarded. The copepods were sorted out by examining the residue under a binocular microscope. Attempts to pick out some of the copepods alive seldom meet with success as they tend invariably to hide under some coverage, thus making it difficult to spot them. All the species are present in fairly good numbers. The type specimens are deposited at the Reference Collection 
Museum of the Central Marine Fisheries Research Institute, Mandapam Camp. The description and the diagrams are based on the examination of more than one specimen. All the drawings have been made with the aid of a camera lucida.

\section{Section SIPHONOSTOMA}

Family Astrerocheridae Giesbrecht s. str.

Sars, 1918, p. 83 .

(Syn. Ascomyzontidat Sars)

Nicholls, 1944, p. 16.

Genus Asteropontius Thompson \& Scott 1903

Thompson \& Scott, 1903, p. 288.

Asteropontitus littoralis sp. nov.

Material examined-Many specimens were collected during the months of June and July 1960. Most of the specimens were obtained from the Palk Bay off Mandapam and a few examples were also caught near the Pamban bridge, the meeting place of Gulf of Mannar and Palk Bay. The holotype and paratypes are deposited in the Central Marine Fisheries Research Institute and bear the registered Nos. J. $535 / 4$ and J. 536/4 respectively.

\section{Description: A. Female}

The body (Fig. I, 1): The general appearance is typically asterocherid. The prosome is distinctly oval and is composed of four segments. The first segment is longer than the length of all other segments combined. The latter diminish gradually in width, the last of them being less than half as wide as the first. The urosome (Fig. I, 12) is only half the length of the prosome and consists of the fifth leg-bearing segment, the genital segment and two abdominal segments. The genital segment is the largest and has its anterior region wider than the posterior; at the junction of these two, there are tufts of hairs on either side. Urosomal segments are wider in front, gradually narrowing posteriorwards. Each caudal ramus bears six setae, one of which is distinctly longer than the entire urosome.

Antennule (Fig. I, 2) is 19-segmented and reaches to the posterior margin of the first prosomal segment. The segments of the antennule are divisible into a wider proximal and a narrower distal region, consisting of nine and ten segments respectively. All the segments are provided with setae, more than one in many cases, especially on ninth to eleventh segments where there is a profusion of setae. The eighteenth segment bears a fairly long aesthetask. The proportions of the various segments are given below (All segments are measured through the middle line).

$\begin{array}{ccccccccccc}1 & 2 & 3 & 4 & 5 & 6 & 7 & 8 & 9 & 10 & \\ 13.2 & 2.6 & 3.1 & 4.0 & 3.5 & 3.3 & 4.4 & 4.4 & 4.4 & 1.8 & \\ 11 & 12 & 13 & 14 & 15 & 16 & 17 & 18 & 19 & & \\ 2.6 & 5.3 & 6.6 & 7.0 & 5.3 & 6.2 & 5.9 & 7.0 & 9.4 & & =100\end{array}$




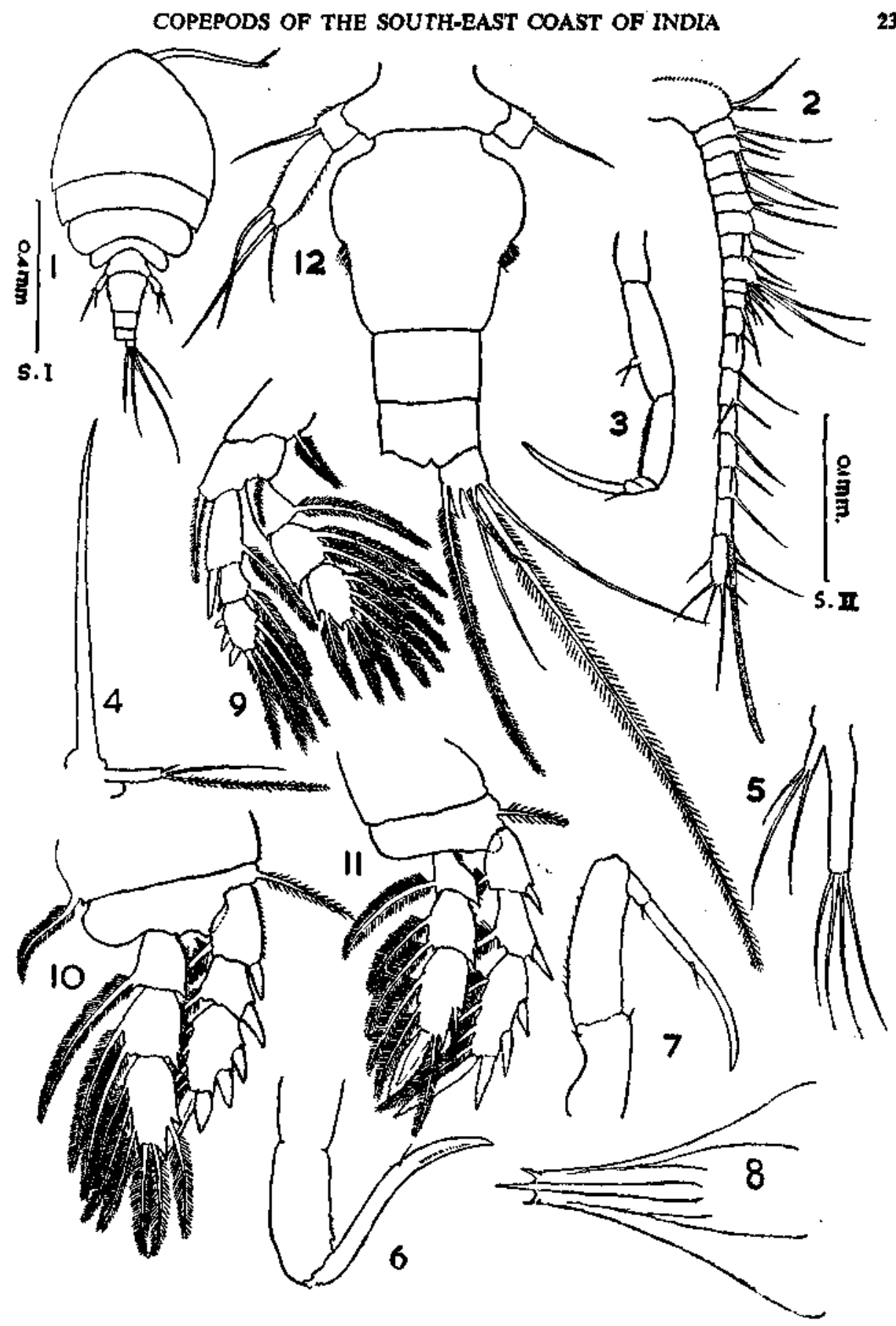

Figure I, 1-12. Asteropontius Ittoralis sp. nov.

1. Adult, female, dorsal view.

2. " " antennule.

3. " " antenna.

4. " " " mandible.

5. " " maxillule.

6. " " maxilla.

(Diagram 1 is drawn according to scale $I$ and diagrams" $2-12$ according to scalo II). 
Antenna (Fig. I, 3) is 5-segmented ; the last two segments, however, are not fully segmented. The second segment is the largest, the third, first, fourth and the fifth coming next in order. The second segment bears at about two-third of its length a rudimentary endopod which carries two small setae on the apex. The terminal antennal segment bears a fairly large spine and a stout seta at its apex. Hairs are present on the inner margin of the third segment. Siphon (Fig. I, 8) is stoutly built, pyriform in shape and only extending to the insertions of the maxillipeds; its posterior edge is marked by three sharply spine-like structures, one medial and two lateral. Mandible (Fig. I, 4) is with a very long masticatory blade and a short uniarticulate palp which bears at its apex three setae of unequal length. The blade is five times as long as the palp. This condition is not found in any other known species of this genus. Maxillule (Fig. I, 5), as usual, is composed of two lobes which are much unequal in size. Both the lobes are provided with a number of apical setae which are rather strong and finely ciliated. Maxilla and maxilliped (Fig. I, 6 \& 7) are of the usual asterocherid pattern, the only notable difference being that in the former the line of separation between first and second segments are not distinct although there is a clear constriction between them.

The four pairs of swimming legs (Fig. I, 9, 10 \& 11) are borne by the four prosomal segments. They are all biramous, each ramus being composed of three segments. In the first legs, the basal exopodosegment is elongated, almost equivalent to the combined length of second and third segments. The spine on that segment also is quite long. The second and third legs are very similar to each other in structural details and are quite normal. In the fourth leg the segments of both endopod and exopod are slender and long and differ from those of the preceding legs in setation. The setal formula of the four pairs of swimming legs are given below :- (In this and in all the subsequent accounts of the ornamentation of the swimming legs the following abbreviations have been used: $\mathbf{P}_{1}-\mathbf{P}_{4}$ stand for the first to the fourth swimming legs and $\mathrm{Si}$, Se and $\mathrm{St}$ reptesent the internal, the external and the terminal margins respectively of the constituting segments. The setae are indicated in Arabic and the spines in Roman numbers).

\begin{tabular}{|c|c|c|c|c|c|c|c|c|c|c|c|c|c|c|c|c|c|c|}
\hline \multicolumn{5}{|c|}{ Protopod } & \multicolumn{7}{|c|}{ Endopod } & \multicolumn{7}{|c|}{ Exopod } \\
\hline & \multicolumn{2}{|c|}{1} & \multicolumn{2}{|c|}{2} & \multicolumn{2}{|c|}{1} & \multicolumn{2}{|c|}{2} & \multicolumn{3}{|c|}{3} & \multicolumn{2}{|c|}{1} & \multicolumn{2}{|c|}{2} & \multicolumn{3}{|c|}{3} \\
\hline & $\mathbf{S i}$ & $\mathrm{Se}$ & $\mathbf{S i}$ & Se & Si & Se & $\mathrm{Si}$ & $\mathrm{Se}$ & $\mathbf{S i}$ & & Se & $\mathrm{Si}$ & $\mathrm{Se}$ & $\mathbf{S i}$ & Se & $\mathrm{Si}$ & St & Se \\
\hline $\mathbf{P}_{\mathbf{1}}$ & 1 & 0 & 1 & 1 & 1 & o & 2 & 0 & 3 & 2 & 1 & 1 & I & 1 & I & 2 & 2 & III \\
\hline $\mathbf{P}_{\mathbf{z}}$ & 1 & 0 & 0 & 1 & 1 & 0 & 2 & 0 & 3 & 2 & 1 & 1 & I & 1 & $\mathbf{I}$ & 4 & II & II \\
\hline $\mathbf{P}_{3}$ & 1 & 0 & 0 & 1 & 1 & 0 & 2 & 0 & 3 & 2 & 1 & 1 & $I$ & I & I & 4 & II & II \\
\hline$P_{4}$ & 0 & 0 & 0 & 1 & 1 & 0 & 2 & $\mathbf{0}$ & 2 & $\mathrm{I}+$ & & 1 & I & 1 & I & 4 & II & I II \\
\hline
\end{tabular}

The ffith leg (Fig. I, 12) is quite moderate in size, reaching upto the middle of the genital segment. It consists of two segments of unequal size; the basal bears a single seta and the distal three setae, two of which are apical and the third subapical. Stiff hairs are present on the outer margin of the basal and on both margins of the distal segment. The size of the adult female is $0.8 \mathrm{~mm}$. 


\section{B. Male}

Unknown.

Asteropontius sewelli sp. nov.

Material examined-Four specimens were obtained from the washings of the bottom weeds from Palk Bay in June 1960. All are females. The holotype and the paratypes are deposited in the Central Marine Fisheries Research lnstitute, Mandapam Camp and have the registered Nos. J. 569/5 and J. 570/5 respectively.

\section{Description: $\quad$ A. FemalB}

The body (Fig. II, 1)-Like the preceding species, here also, the body is more or less oval. The first prosomal segment is, however, much wider and longer than the other three segments combined. The urosome consists of four segments, the genital segment being the largest. The latter is vase-like, with the anterior part wider than the posterior and the two areas being separated by tufts of hairs on the lateral margins. The post-genital segments are cylindrical and narrow. The caudal ramus is short and distinctly smaller than the last abdominal segment ; each ramus bears six setae, the longest of them being one and a half times longer than $112 \mathrm{e}$ entire urosome ; it is 2-segmented and profusely setiferous.

The antennule (Fig. II, 2) is fairly long reaching to the posterior margin of the first prosomal segment. It consists of nineteen segments, the first nine segments being distinctly wider and longer than the remaining segments. The eighteenth segment bears an aesthetask which is rather short. The proportionate lengths of the antennular segments are as follows:-

$\begin{array}{lllllllllll} & 1 & 2 & 3 & 4 & 5 & 6 & 7 & 8 & 9 & \\ & 8.69 & 3.00 & 2.55 & 2.78 & 2.55 & 2.33 & 2.21 & 2.55 & 2.33 & \\ 10 & 11 & 12 & 13 & 14 & 15 & 16 & 17 & 18 & 19 & \\ 1.23 & 1.47 & 5.85 & 7.36 & 8.69 & 8.69 & 9.49 & 8.68 & 9.75 & 9.81=100\end{array}$

Antenna (Fig. II, 3)-is 5-segmented and quite normal in structure. The second segment bears the rudimentary endopod; there are two short spines and a long spine on the terminal segment. Siphon (Fig. II, 4) is very short and stout, having two sharp needle-like points at the posterior tip; no medial spine is present. In the mandible (Fig. II, 5) the masticatory blade is very long and pointed while the palp is uniarticulate and rather short, bearing two setae, one of which is cxtremely long, being longer than the masticatory blade and ciliated on both nargins. Maxillule (Fig. II, 6) consists of two lobes which are very much unequal in size, the smaller one being only one-fifth of the larger and appearing more as a process of the latter. Maxilla and maxilliped (Fig. II, 7 \& 8) are quite normal and similar to those of the preceding species. The terminal claw of the maxilla, however, is much more slender and long.

Of the four pairs of swimming legs (Fig. II, 9, 10 \& 11) which are borne by the four prosomal segments respectively, the first leg is the smallest. The second and 


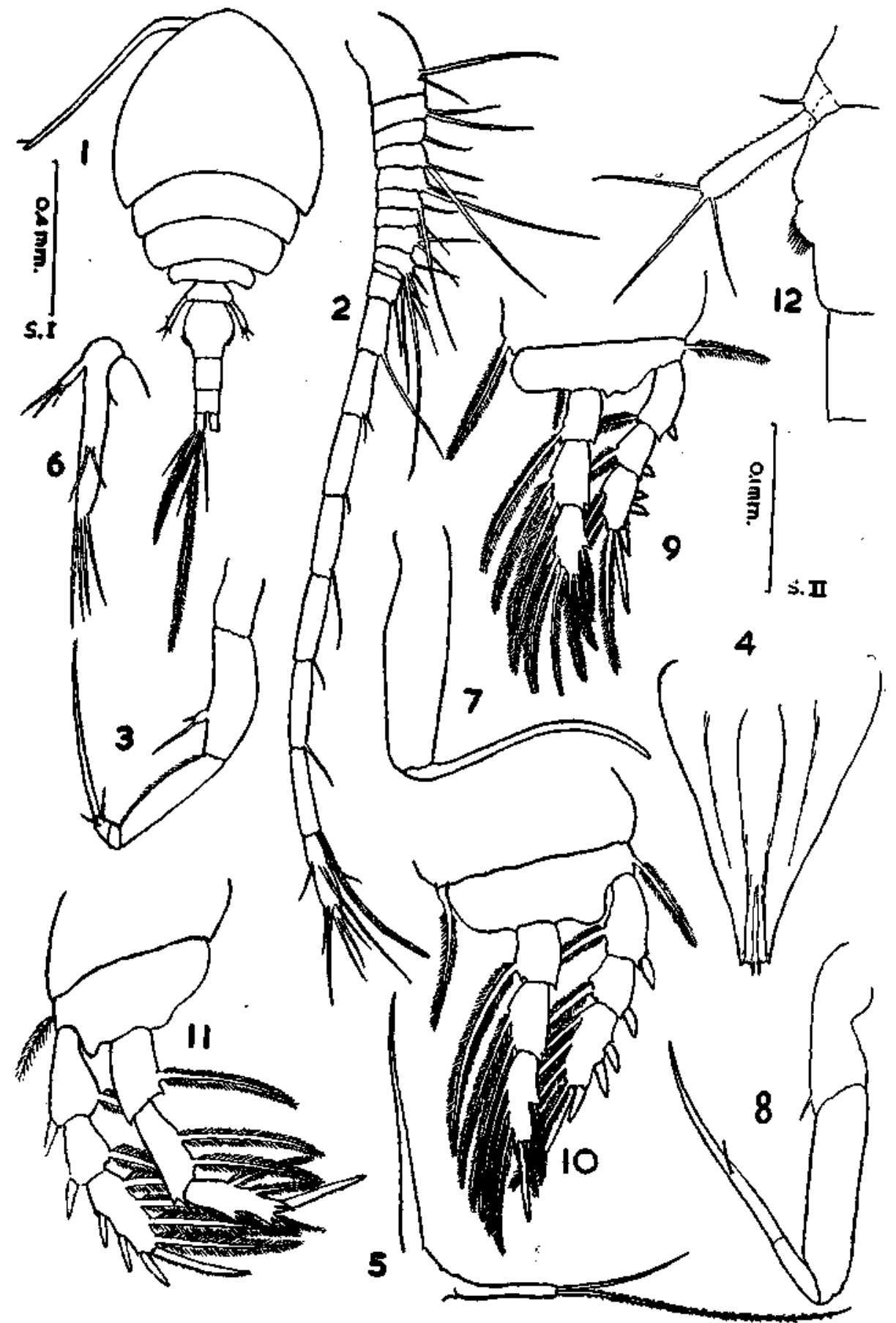

Figure II, 1-12. Asteropontius sewell, sp. nov.

1. Adult, female, dorsal view.

2. " " antennule.

3. " " " antenna.

4. " " siphon.

5. " " mandible.

6. " " maxillule.

(Diagram 1 drawn according to scale I and diagrams 2-12 according to scale II). 
third legs are exactly similar in structure and appearance. In the fourth leg the constituting segments are longer than those of the preceding legs. The setal formula of the swimming legs is as follows :-

\begin{tabular}{|c|c|c|c|c|c|c|c|c|c|c|c|c|c|c|c|c|c|c|}
\hline & \multicolumn{4}{|c|}{ Protopod } & \multicolumn{7}{|c|}{ Endopod } & \multicolumn{7}{|c|}{ Exopod } \\
\hline & \multicolumn{2}{|c|}{1} & \multicolumn{2}{|c|}{2} & \multicolumn{2}{|r|}{1} & \multicolumn{2}{|c|}{2} & \multicolumn{3}{|c|}{3} & \multicolumn{2}{|c|}{1} & \multicolumn{2}{|c|}{2} & \multicolumn{3}{|c|}{3} \\
\hline & $\mathbf{S i}$ & Se & $\mathbf{S i}$ & Se & $\mathrm{Si}$ & $\mathrm{Se}$ & $\mathrm{Si}$ & $\mathrm{Se}$ & Si & $\mathrm{St}$ & $\mathrm{Se}$ & Si & $\mathrm{Se}$ & $\mathbf{S i}$ & $\mathrm{Se}$ & $\mathrm{Si}$ & $\mathbf{S t}$ & Se \\
\hline $\mathbf{P}_{1}$ & 1 & 0 & 1 & 1 & 1 & 0 & 2 & 0 & 3 & 2 & 1 & 1 & I & 1 & I & 2 & $1+I$ & III \\
\hline$P_{2}$ & 1 & $\mathbf{0}$ & 0 & 1 & 1 & 0 & 2 & 0 & 3 & $I+1$ & 1 & 1 & $\mathbf{I}$ & 1 & I & 4 & I & II \\
\hline $\mathbf{P}_{\mathbf{a}}$ & 1 & 0 & 0 & 1 & 1 & 0 & 2 & 0 & 3 & $I+1$ & 1 & I & $\mathbf{I}$ & 1 & I & 4 & I & II \\
\hline P. & 0 & 0 & 0 & 1 & 1 & 0 & 2 & 0 & 2 & $I+1$ & 1 & 1 & I & 1 & $\mathbf{I}$ & 4 & I. & III \\
\hline
\end{tabular}

It may be seen from the above that the terminal endopod segment in the second, third and fourth pairs of legs bears one seta and one spine instead of the usual single spine or single seta. The fifth leg (Fig. II, 12) is fairly long and thin and is 2-segmented, the proximal segment being contained about four times in the distal segment; the former bears a single seta at its postero-lateral corner and the latter three radiating setae on the apex. There are stiff hairs on either margins of the distal segment. The size of the female is $1.1 \mathrm{~mm}$.

\section{Unknown.}

\section{B. MALE}

This species is named after Col. R. B. S. Sewell, C.I.B., Sc.D., F.R.S., in recognition of the very valuable contributions that he has made towards our understanding of the Indian copepods.

Remarks-Thompson \& Scott (1903) created this genus to include two species of copepods, $A$. typicus and $A$. attenuatus which they obtained from the sponge and invertebrate washings. Since then two more species have been added, $A$. nicobaricus Sewell from Nicobar Islands and A, mycalei Krishnaswamy, from Madras. The genus is very closely related to Asterocheres and can be distinguished only on careful examination. Thompson \& Scott defined the genus Asteropontius as follows : - Cephalothorax roundly ovate, five-jointed, the cephalic segment larger than the combined length of the four following segments. Anterior antenna 18-19 jointed. Abdomen 3-jointed. Outer branch of the posterior antenna 4-jointed, a small 1-jointed branch springing from the first joint. Maxilla 2-branched. Mandible long and narrow; palp i-jointed. Maxilliped and natatory legs 1st to 5th as in Asterocheres' (loc. cit. p. 288). They remarked at the end of the description of $A$. typicus that ' the species bears a general resemblance to Asterocheres, but the 19jointed antennae and the 1-jointed mandible palp separate therefrom.' The antennular segmentation does not hold valid as a generic character for the number of segments in the antennule is now established to vary from eighteen to twenty in Asteropontius and fourteen to twenty in Asterocheres. The statement that the antenna is 4-jointed and that the rudimentary endopod is borne by the basal antennal segment does not conform to their diagrams (PI. XVIII, Fig. 13 \& PI. XIX, Fig. 3) 
which clearly show that antenna is 5-jointed in both the species, and that the rudimentary endopod is borne by the second segment. In $A$. nicobaricus the antenna is 5 -jointed, the proportions of the different segments being almost identical with those of the preceding two species. $A$. mycalei has an antenna which is 3 -jointed; it appears from the diagram of the latter species that the last two segments have undergone a fusion. The fact, however, is clear that as far as the segmentation of the antenna is concerned no distinction can be made between the two genera. Thus the only distinguishing feature of the genus Asteropontius, not shared by Asterocheres, is the uniarticulate nature of the mandibular palp.

The third segment of the first exopod also deserves some comments. Three types of conditions are met with in the present genus. In $A$. typicus there are four setae and two spines. In $A$. attenuatus the number of setae are four and that of spines three ; this latter condition is also found in $A$. nicobaricus and $A$. litroralis sp. nov. A third type of situation occurs in $A$. mycalei and $A$. sewelli $\mathrm{sp}$. nov.; here there are three setae and four spines. Thus the tendency towards an increase in the number of spines is accompanied by a reversed tendency in the case of setae.

Krishnaswamy (loc. cit.) has provided a key to the identification of the different species known upto that time. The number of segments of the antennule was the main criterion on which his key was based. It now appears that the number of setae and spines on the third segment of the first exopod also provides a good point of specific distinction and the identification key is here revised employing these two characters along with the structure of the caudal rami when it is required.

Key to the identification of the females

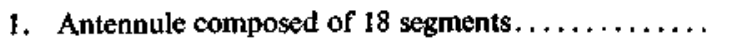
Antennule composed of 19 segments

$\ldots \ldots \ldots+\ldots \ldots+\ldots, \ldots$

2. Caudal rami Ionger than wide, the proportions of length and width being $5: 2$

Caudal rami wider than long, the proportions of length and width being $4: 5 \ldots \ldots \ldots \ldots \ldots$ A. nicobaricus Sewell, 1949.

3. The third segment of first exopod with four setae and two spines

A. typicus Thomp. \& Scott, 1903.

The third segment of first exopod with four setae and

A. littoralis sp. nov. three spines

The third segment of first exopod with three setae and four spines

A. sewelli sp. nov. 


\section{Family DYSPONTIIDAe SARS}

Sars, 1918 , p. 117.

Nicholls, 1944, p. 23.

Genus Cryptopontius GIEsBRECHT, 1899

Sars, 1918, p. 120.

Nicholls, 1944, p. 24.

Cryptopontius Graciloides Sp. Nov.

Material examined.-Fourteen female specimens were obtained from washings of weeds from the Palk Bay. They were captured on two occasions. No specimen was available from the Gulf of Mannar even after many searches. The holotype and paratypes are deposited in the Central Marine Fisheries Research Institute and bear the registered numbers $J .572 / 6$ and $J .573 / 6$ respectively.

\section{Description: $\quad$ A. Female}

The body (Fig. III, 1).---The prosome consists of four segments and the urosome of five segments. . The first prosomal segment is very large being distinctly larger than the rest of the body. It is slightly wider than long and the length-brcadth proportion is $48: 52$. Second and third segments are less wide than the first segment but still with epimeral plates which are crowded together and curved backwards. The last prosomal segment is very small without epimeral plates and partly concealed by the preceding segment. The first segment of the urosome bears the highly reduced fifth pair of legs. It is only about as large as the last prosomal segment. The genital segment (Fig. III, 8) is quite large, being equivalent in length to the combined length of the three following segments. Its anterior part is very much widened, more than twice as wide as the last abdominal segment, and bears on each side a pair of spines towards the postero-lateral margin of the widened area. Of the three abdominal segments the first is the longest, and the second the shortest. They diminish in width posteriorly. The caudal ramus is a little wider than long and bears six selae, one of which is very long, being more than twice as long as the entire urosome ; the furcal setae are plumose.

Antennule (Fig. III, 2) is 9-segmented and rather stout. The first, third and the last segments are fairly long; second segment is the shortest and is distinctly wider than long; the fifth segment is square. Other segments are of moderate length and are longer than wide. The last segment bears an aesthetask which is about twothird the length of the antennule itself. Following are the proportions of the different segments :-

$\begin{array}{llllllllll}1 & 2 & 3 & 4 & 5 & 6 & 7 & 8 & 9 & \\ 18.2 & 3.8 & 19.5 & 7.2 & 6.0 & 8.3 & 8.3 & 9.8 & 18.9=100\end{array}$

Antenna (Fig. III, 3) is 4-segmented, the second segment carrying a rudimentary endopod bearing a single terminal seta. The second, third and fourth segments are of about equal lengths while the basal segment is distinctly shorter. The terminal segment bears three setae, one at about its mid-length on the ventral side and the 


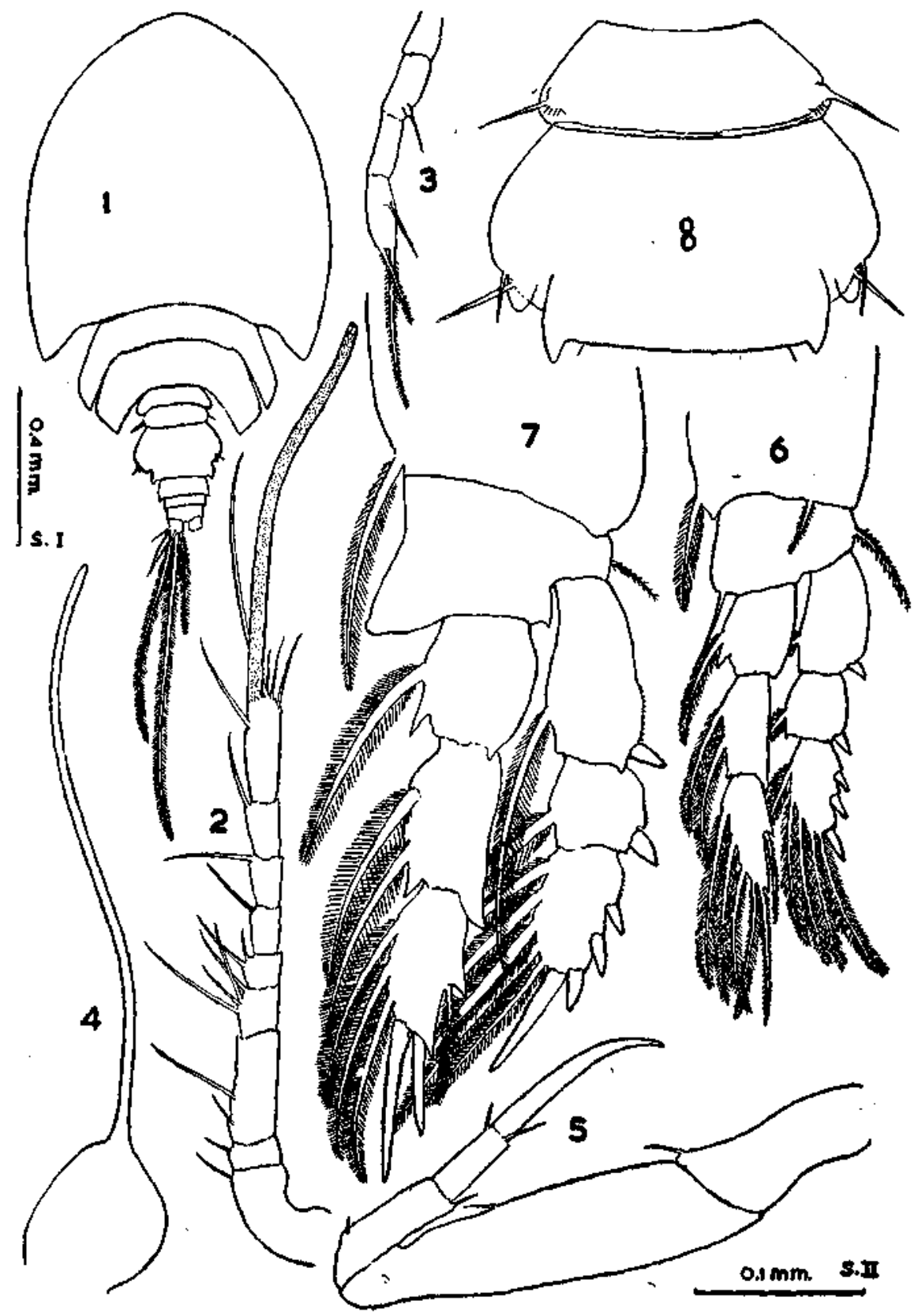

Figure III, 1-8. Cryptopontitus graciloides, sp, nov,
1 Adult, female, dorsal view.
5. Adult, female, maxilliped.
2. " " antennule, 6. " " first swimming leg.

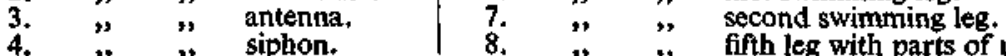
8. " " fifth leg with parts of urosome.
(Diagram 1 is drawn according to scale I and diagrams 2-8 according to scale II). 
other two terminally ; the terminal setae are of unequal length. Siphon (Fig. III, 4) is extremely slender and consists of a bulbous proximal portion and a narrow distal portion which is of uniform thickness throughout and which extends almost to the end of the prosome. Mandible without any palp, masticatory blade slender, styliform and long. Maxillule (Fig. IV, 1) has both lobes slender, the outer more than three-fourth as long as the inner and armed with a very short spine and a fairly long seta ; the inner lobe bears on its apex a spine, and a seta, the latter being more than one and a half times longer than the lobe itself and provided with stiff hairs on the inner margin. The maxillae and maxillipeds (Fig. IV, 2 \& III, 5) are normal in structure and resemble those of the type species of the genus.

The four pairs of swimming legs (Fig. III, 6, 7 and Fig. IV, 3) are borne by the four prosomal segments respectively. First three pairs are biramous while the fourth is uniramous, the endopod entirely lacking. While the second and third legs are similar to each other in structure and size, the first is distinctly smaller and shows differences in the setation. The setal formula of the swimming legs is given below :

\begin{tabular}{|c|c|c|c|c|c|c|c|c|c|c|c|c|c|c|c|c|c|c|}
\hline & \multicolumn{4}{|c|}{ Protopod } & \multicolumn{7}{|c|}{ Endopod } & \multicolumn{7}{|c|}{ Exopod } \\
\hline & \multicolumn{2}{|c|}{1} & \multicolumn{2}{|r|}{2} & \multicolumn{2}{|c|}{ 」 } & \multicolumn{2}{|c|}{2} & \multicolumn{3}{|c|}{3} & \multicolumn{2}{|c|}{1} & \multicolumn{2}{|c|}{2} & \multicolumn{3}{|c|}{3} \\
\hline & $\mathrm{Si}$ & $\mathrm{Se}$ & Si & Se & $\mathrm{Si}$ & $\mathrm{Se}$ & $S i$ & $\mathrm{Se}$ & $\mathrm{Si}$ & $\mathbf{S t}$ & $\mathrm{Se}$ & $S$ & $\mathrm{Se}$ & $S i$ & Se & Si & St & Se \\
\hline $\mathbf{P}_{\mathbf{x}}$ & 1 & 1 & I & 1 & 1 & 0 & 2 & 0 & 4 & 1 & 1 & $\mathrm{t}$ & I & I & I & 4 & 1 & III \\
\hline $\mathbf{P}_{2}$ & 1 & 0 & 0 & 1 & 1 & 0 & 2 & 0 & 3 & II & 1 & 1 & I & 1 & I & 5 & I & III \\
\hline $\mathbf{P}_{s}$ & 1 & 0 & 0 & 1 & I & 0 & 2 & 0 & 3 & II & I & 1 & I & $\mathbf{1}$ & I & 5 & 1 & III \\
\hline $\mathbf{P}_{4}$ & 0 & 0 & 0 & 0 & - & - & $A$ & ase & t - & 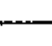 & & 1 & $\mathbf{I}$ & 1 & I & 5 & & III \\
\hline
\end{tabular}

The fifth legs (Fig. III, 8) are extremely rudimentary and are represented on each side by a single seta borne on a bud-like protrusion; there are a few stiff hairs on the lower margin of this bud. The size of the female is $1.3 \mathrm{~mm}$.

\section{B. Male}

Unknown.

Cryptopontius orientalis sp. nov.

Material examined--Along with the preceding species, two female examples, each carrying a pair of beautifully rose-coloured ovisacs were obtained from Palk Bay in June, 1960. A few weeks after that some more examples, about fifteen specimens, were caught near the Pamban Bridge and the latter collection included both males and fernales. The type specimens, the holotype, the allotype and the piratypes are deposited in the Central Marine Fisheries Research Institute and bear the registered numbers $\mathrm{J} 658 / 7, \mathrm{~J} 659 / 7$ and $\mathrm{J} 660 / 7$ respectively.

\section{Description: A. Female}

Although the ovisacs are of fine rose colour, the body is dull opaque, as in most of the cyclopoides. The ovisacs also lost their colour after a few days of preservation in formalin. The body (Fig. IV, 4)-This is more robust than in the preceding 


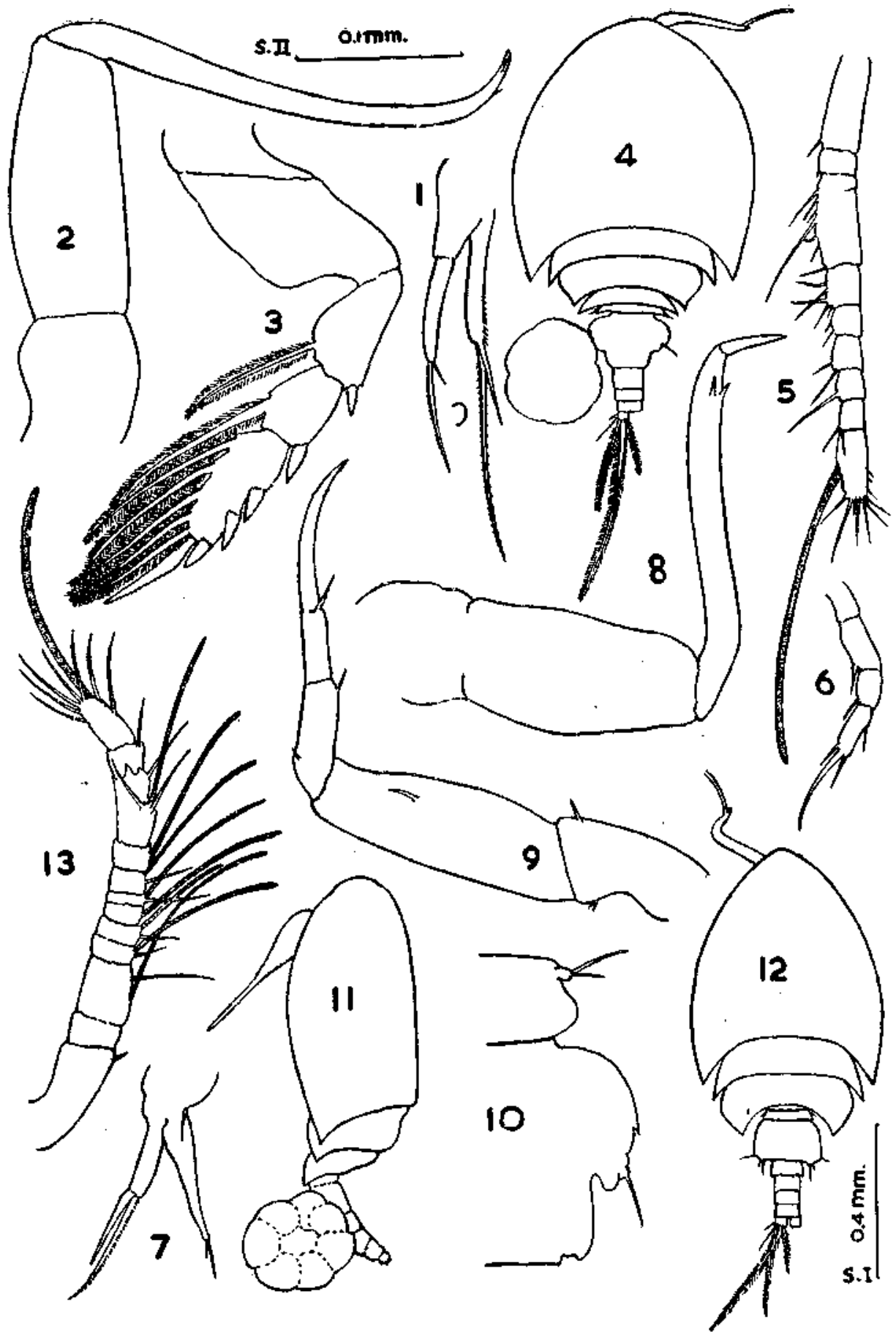

Figure IV, 1-13. Cryptopontius graciloides sp. nov.

1. Adult, female, maxillule.

3. Adult, fernale, fourth swimming leg.

maxilla. Cryptopontius orientalis sp. nov.

4. Adult, female, dorsal view. 9. Adult, femals, maxilliped.

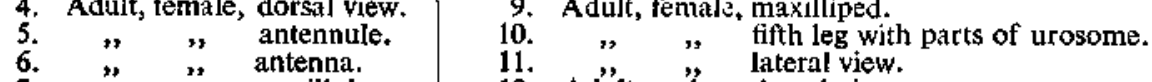

7. " " maxillule. 12. Adult, male, dorsal view.

8. " " maxilla. "13. " " antennule.

(The fourth, eleventh and twelfth diagrams are "drawn "according to scale I and others accordins to scale $\amalg$ ). 
species and the first prosomal segment still constitutes the major part of the body. It is wider than long and is one-quarter time longer than the entire remainder of the body. Second and third prosomal segments are less wide but are provided with epimeral plates. The last segment is very small both in length and width and is without an epimeral plate but is provided with posterior angular corners like the preceding segments. The urosome is 5-segmented and is much similar to that of the earlier species. The anterior part of the genital segment, however, is comparatively wider. Although the three abdominal segments diminish in size posteriorly, the ratio of the length is different from that of the earlier species. The caudal rami are wider than long, each bears five setae, two of them appearing morellike spines; the longest seta is one and a half times longer than the entire urosome.

Antenmule (Fig. IV, 5) is 9-segmented, the third segment showing a slight partial division. Segments $1-3,5$ and 9 are of the same length-width relations as in the preceding species, while the fourth, sixth, seventh and eighth segments are much shorter and are only a little longer than wide. The last segment bears an aesthetask which is about three-fourth as long as the entire antennule. The proportionate lengths of the constituting segments are :-

$$
\begin{array}{rrrrrrrrrr}
1 & 2 & 3 & 4 & 5 & 6 & 7 & 8 & 9 \\
22.0 & 5.1 & 19.8 & 8.8 & 6.9 & 7.8 & 6.9 & 6.9 & 15.8 & =100
\end{array}
$$

Antenna (Fig. IV, 6) is 4-segmented, the second segment bearing the rudimentary endopod. The basal segment is equivalent to the third in length and is shorter than the second and fourth which are more or less of equal dimensions. While the third segment bears a single seta, the fourth has four of them, one at about half its length and three terminally. The setae are unequal in size. Mandible is quite normal and typical of the genus. Maxillule (Fig. IV, 7) has both lobes slender, the outer two-third as long as the inner and armed with a seta and a spine; the inner lobe armed with two slender spines; at the base of the inner lobe there is another spine. Maxilla and maxilliped (Fig. IV, 8 \& 9) bear a great resemblance to those of the earlier species. A notable difference in the maxilla, however, is that the division between the first and the second segment is incomplete. In the maxilliped, the basal segment bears a pair of small spines on the outer distal margin, in addition to the one present on the inner distal margin.

First three pairs of swimming legs (Fig. V, 1, 2 \& 3) are biramous, while the fourth is uniramous, the endopod entirely missing. The legs two and three are absolutely identical in structure and size, while the first leg is smaller. The outer margins of all the segments of the exopods of second, third and fourth legs are clearly dentate. The setal formula for the swimming legs is given below:

\begin{tabular}{|c|c|c|c|c|c|c|c|c|c|c|c|c|c|c|c|c|c|c|}
\hline & \multicolumn{4}{|c|}{ Protopod } & \multicolumn{7}{|c|}{ Endopod } & \multicolumn{7}{|c|}{ Exopod } \\
\hline & \multicolumn{2}{|c|}{1} & \multicolumn{2}{|c|}{2} & \multicolumn{2}{|c|}{ I } & \multicolumn{2}{|c|}{2} & \multicolumn{3}{|c|}{3} & \multicolumn{2}{|c|}{1} & \multicolumn{2}{|c|}{2} & \multicolumn{3}{|c|}{3} \\
\hline & $\mathrm{Si}$ & $\mathrm{Se}$ & $\mathrm{Si}$ & $\mathrm{Se}$ & Si & $\mathrm{Se}$ & $\mathbf{S i}$ & Se & Si & $\mathrm{St}$ & $\mathrm{Se}$ & $\mathrm{Si}$ & $\mathrm{Se}$ & Si & Se & $\mathrm{Si}$ & $\mathrm{St}$ & So \\
\hline$P_{1}$ & 1 & 0 & $\mathbf{I}$ & 1 & 1 & 0 & 1 & 0 & 4 & 1 & 1 & 1 & I & 1 & $\mathbf{I}$ & 3 & 1 & III \\
\hline $\mathbf{P}_{\mathbf{Z}}$ & 1 & 0 & 0 & 1 & 1 & 0 & 2 & 0 & & $I+1$ & 1 & 1 & I & 1 & I & 5 & I & III \\
\hline $\mathbf{P}_{3}$ & 1 & 0 & 0 & 1 & 1 & 0 & 2 & 0 & & $I+1$ & 1 & 1 & I & 1 & I & 5 & I & III \\
\hline$P_{\downarrow}$ & 0 & 0 & 0 & 0 & 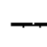 & 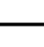 & $\mathrm{Ab}$ & ser & $\ldots$ & & m & 1 & $I$ & 1 & I & 5 & I & III \\
\hline
\end{tabular}


The number of setae and spines of the third segment of first exopod is different from that of the earlier species; while in the latter there are five setae and three spines, here the number of setae is reduced to four. Further the setae on the inner side of the third endopod segment of the first leg is very small compared to that of the earlier species. Fifth leg (Fig. IV, 10) is highly reduced in size and it is represented on each side by a prottusion which bears two slender setae at its apex. The size of the female is $1.05 \mathrm{~mm}$.

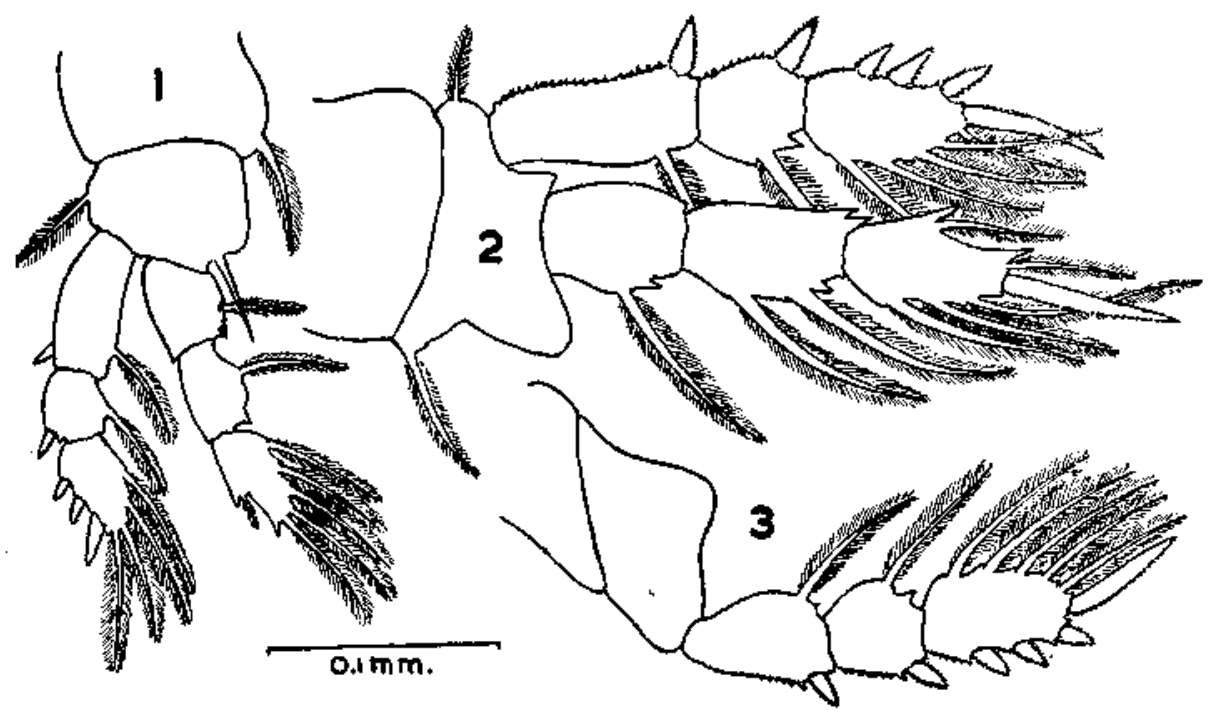

Figure V, 1-3. Cryptopontius orientalis sp. nov.

1. Adult, female, first swimming leg.

2 . " " second swimming leg

3. " " " fourth swimming leg.

\section{B. Male}

The general body (Fig. IV, 12) of the male is more slender than that of the female. While in the former the first prosomal segment is only one-quarter time as wide as that of the second prosomal segment, in the latter it is one and a half times wider. The last prosomal segment in formalin preserved specimens is entirely concealed by the preceding segment. The urosome consists of six segments. The genital segment is very large, equivalent in length to the three following abdominal segments. But unlike in the female it is more or less of uniform width and bears on each side posteriorly three spines, two of them directed backwards and the third sidewards. The abdominal segments diminish slightly, both in width and length, towards the posterior side. The caudal ramus is wider than long and bears the same number of setae, with same proportionate lengths, as in the female. The size of the male is $1.0 \mathrm{~mm}$.

Antennule (Fig. IV, 13) is geniculate on both sides. It is 12-segmented, with the first segment being the longest and seventh the shortest. The tenth segment is somewhat dilated, exhibiting near the end, in front, a short dentiform projec- 
tion. Segments 3-10 bear each an aesthetask which is fairly long. The last segment also bears an aesthetask which is corresponding to that of the female. The proportionate lengths of the different segments are given below:

$\begin{array}{cccccccccrrrr}1 & 2 & 3 & 4 & 5 & 6 & 7 & 8 & 9 & 10 & 11 & 12 & \\ 21.6 & 5.5 & 13.1 & 4.5 & 4.5 & 4.0 & 2.5 & 5.2 & 4.2 & 15.7 & 6.0 & 13.2 & =100\end{array}$

The setae on the antennule of the male are longer compared to those of the antennule of the female. All other appendages including the fifth legs are identical to those of the female sex; but they are relatively smaller.

Remarks-Nicholls (1944) has reviewed this genus and pointed out that it contains ten species including the four new species he added from the Australian waters. So far only one species has been reported from the Indian waters, $C$. brevifurcatus, recorded from Madras coast by Krishnaswamy (loc. cit.). The addition of the two present species brings the total number of known forms to twelve and shows that the genus probably is quite represented in our waters. The genus is very closely related to Dyspontius and the most reliable character by which they are distinguished is the armature of the first exopod: Dyspontius has only two outer spines on the end segment, whereas Cryptopontius has three. Wilson's definition $(1932, \mathrm{p} .594)$ of the genus Cryptopontius as having the first prosomal segment longer than wide and third segment of first exopod with three spines and five setae, in contrast to Dyspontius which is said to have the first prosomal segment wider than long and the third segment of the first exopod with three spines and four setae is not correct, as is seen from a glance through the species described so far. All the species of the genus Cryptopontius are consistent in possessing three spines on the end segment of first exopod. The number of setae on that segment and the length-width ratio of the first prosomal segment, however, are not identical in all the species.

As far as the number of setae on the end segment of the first exopod is concerned, two types of situations are met with in the genus. There are five setae and three spines in the case of $C$. brevifurcata Giesb., $C$. proximus Nicholls, $C$. similis Nicholls, $C$. gracilis Wilson and $C$. graciloides sp. nov., while there are only four setae and three spines in the case of $C$. longipes Nicholls, $C$. Latus Nicholls and $C$. orientalis $\mathrm{sp}$. nov. I have not been able to go through the original descriptions of the four remaining species; but the essential specific distinctions are available for the four remaining species, namely, $C$. thorelli Giesb., C. capitalis Giesb., C. innominatus Brady and C. tenuis Giesb. The first two species belong to the second group, namely, the group having four setae and three spines. Of the remaining two species, it is uncertain whether innominatus should be included at all in this genus. 'Brady's specimen was apparently damaged, but the urosome which he figures shows the genital segment of the same width throughout whereas it is characteristic of the genus that it should be very much widened anteriorly' (Nicholls, op. cit. p. 25). Whether the number of setae in the case of $C$. tenvis is four or five could not be known ; presumably it is five as Wilson (op. cit.) has considered that number as the more normal for the genus. However, the fact becomes clear that the species of this genus are separable into two groups, namely, those having five setae in the third segment of the first exopod and those having only four setae on that segment.

C. graciloides is much related to $C$. gracilis but the differences between the two species are many: (i) in C. gracilis the first prosomal segment is as long as wide while here it is slightly wider than long; (ii) in $C$. gracilis the abdominal segments 
decrease in width but increase in length posteriorly ; in C. graciloides the posteriormost segment is the longest and the middle segment the shortest ; in width, here also, they decrease posteriorly; (iii) siphon is short and stout in C. gracilis; the siphon is very long and slender in $C$. graciloides and (iv) size of the female $1.3 \mathrm{~mm}$. in $C$. graciloides; in C. gracilis the female measures only $1.0 \mathrm{~mm}$. and the male $0.85 \mathrm{~mm}$.

$C$. orientalis as noted earlier is close to $C$. longipes and $C$. latus in that in all these three species the terminal exopod segment of first legs carries three spines and four setae. C. longipes, however, is very easily distinguished from the other two species by the fact that in the former the first and second antennulat segments are subequal and much longer than the third antennular segment while in both $C$. latus and $C$. orientalis the second antennular segment is much shorter than the first and third which are subequal. $C$. orientalis is identified from $C$. latus by the following differences: (1) Female of $C$. orientalis measures $1.05 \mathrm{~mm}$. and male $1.0 \mathrm{~mm}$.; the female of $C$. latus is $1.30 \mathrm{~mm}$. long. (2) The genital segment of $C$. latus is shown to be very wide, about three times wider than the following abdominal segment; in $C$. orientalis the genital segment is about two and a half times wider than the next abdominal segment. At the junction of the wider proximal and narrower distal halves of the genital segment of $\mathcal{C}$. orientalis there are two stout spines, on either side directed postero-laterally. In $C$. latus these spines are absent. (3) In C. latus the abdominal segments are more or less of equal dimensions, with the first segment a little longer than the other two segments. In $C$. orientalis the three abdominal segments diminish both in width and length to the posterior side. (4) The rudimentary exopod of the antenna is without any apical seta in C. latus while it is with one apical seta in $C$. orientalis. (5) The larger lobe of the maxillule carries one seta alone in C. latus and two apical and one basal setae in C. orientalis. (6) On the inner margin of the terminal segment of first endopod there is one seta present in the case of $C$. orientalis whereas there is no seta in that position in $C$. latus. (7) The rudimentary fifth leg in $C$. latus bears only a single apical seta while that of $C$. orientalis bears two apical setae.

\section{Section POECILOSTOMA}

\section{Family Clausidijdab Embleton \\ (Syn. Hersilitdae Canu)}

Sars, 1913-1918, p. 144.

Genus Hemicyclops BOECK

Sars, 1913-18, p. 145.

Light and Hartman, 1937, p. 173.

Sewell, 1949, p. 65.

Gooding, 1960, p. 159.

Hemicyclops intermedius sp. nov.

Material examined--Two female specimens were obtained along with other weed washings from the Gulf of Mannar in July 1960. An additional single specimen was obtained from the same area in the following month. The type specimen is deposited in the Central Marine Fisheries Research Institute and bears the registered number $J / 575 / 8$. 


\section{Description :}

\section{A. Female}

This (Fig. VI, 1) is a fairly moderate-sized species with clearly marked prosome and urosome. The prosome is elongate-ovate and comprises the cephalothorax and three free metasomal segments. The cephalothorax is quite large, contains in it the widest part of the body and is longer than the other three prosomal segments combined. The latter gradually diminish in width to the posterior side and are subequal in length. The lateral margin of the third prosomal segment gives an articulated appearance. The posterior margin of the last prosomal segment is truncate in dorsal view. No rostral protuberance is visible dorsally. The urosome is 5segmented and consists of the fifth leg-bearing segment, the genital segment and three abdominal segments. The first segment is small and rather six sided, each lateral margin being set apart into anter-olateral and postero-lateral divisions because of an expanded growth along the mid-transverse line. The fifth legs are borne on the postero-lateral margins. The genital segment is the largest and consists of an anterior wider half and a posterior narrower half which merge into each other without any trace of division between them. The abdominal segments decrease, both in length and breadth, to the posterior side. The combined length of the three abdominal segments is equal to that of the genital segment. The furcal rami are square and a little less long than the last urosomal segment. Each ramus bears five apical setae, one of which is very long, longer than the entire urosome, and one very short and subapical in position.

Antennule (Fig. VI, 2) is 7-segmented. Attachment of the basal segment to the cephalosome is at right angles to the plane of projection of the remainder of the appendage. In life the latter is held perpendicular to the main axis of the body. The relative lengths of the different antennular segments are as follows:

$\begin{array}{cccccccc}1 & 2 & 3 & 4 & 5 & 6 & 7 & \\ 13.8 & 10.6 & 11.2 & 22.4 & 15.2 & 13.4 & 13.4=100\end{array}$

The second segment is the shortest and the fourth the longest. The segments gradually diminish in their thickness to the distal tip. All the segments are provided with a number of setae, especially the second and third segments where there is a profusion of it. Many of the setae bear setules on their margins, several with setules on their tips alone. Antenna (Fig. VI, 3) is 4-segmented. It is twice bent on itself so that it looks like an inverted U-tube, with the first and the fourth segments forming the two limbs of unequal length and the middle two segments forming the base. The basal segment bears two setae on the proximal inner margin and a single seta on the distal outer corner. Tluree groups of 'comb rows' of setae are found on this segment ; one row on the mid-inner margin and two rows on the outer margín, one each in the proximal and distal halves with some space left between the two rows. First segment is the longest. The second segment is almost as equal as the first. It bears on its outer margin at about the mid-length a stout seta which is ciliated on the outer margin. A ' comb row' of setae is present on the outer margin between this seta and the base. The inner margin is uniformly ciliated. The third segment is peculiarly orientated ; its outer lateral margin is bent almost at right angle so that the proximal half of this bent side now becomes the outer lateral margin proper and the distal half becomes the apparent apical margin; the original apical margin is displaced to the position of inner lateral margin ; the real inner lateral margin is highly reduced and constitutes the insignificant proximal 


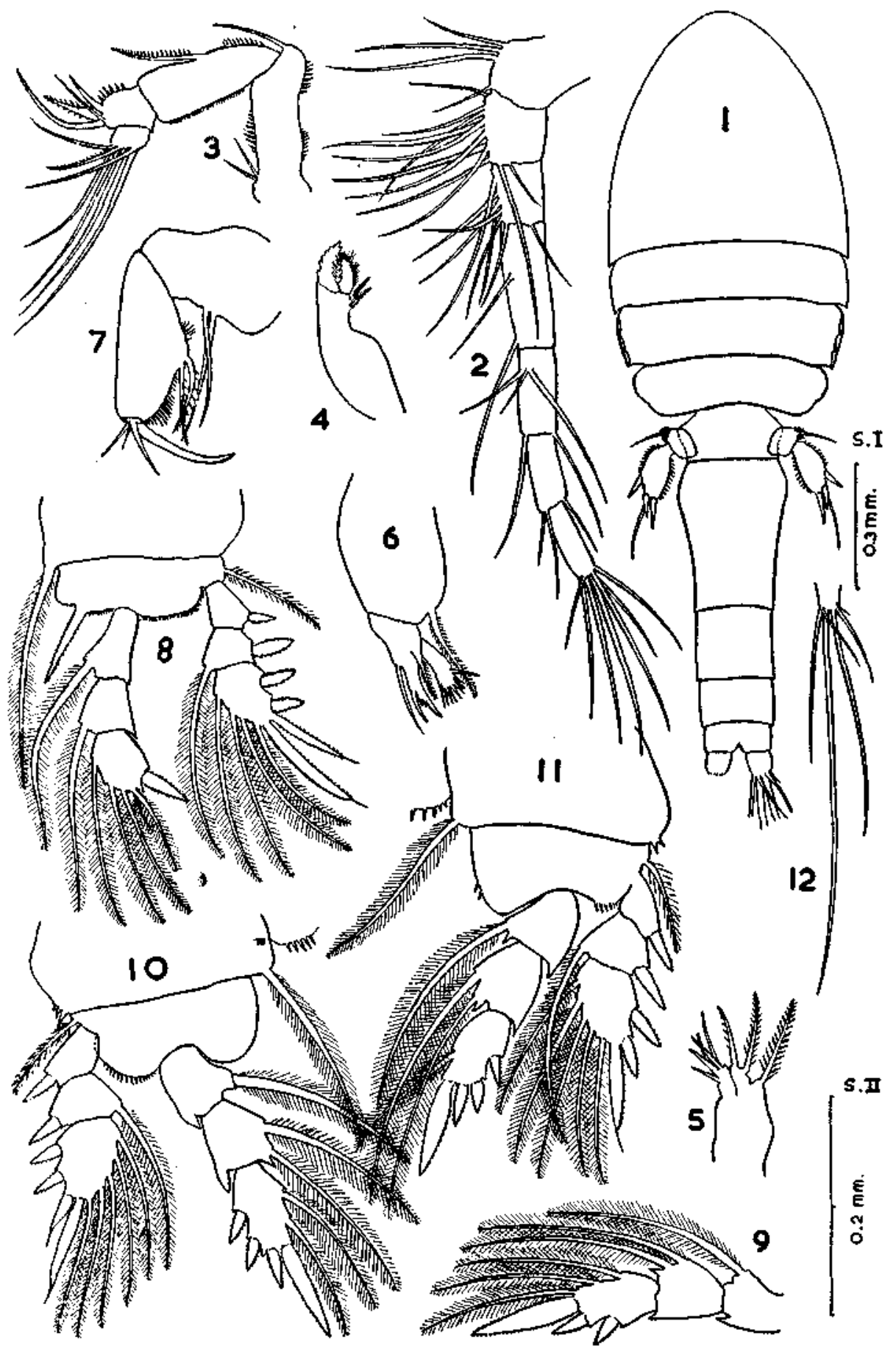

Figure VI, 1-12. Hemicyclops intermedius sp. nov.

1. Adult, female, dorsal view.

2. " " antennule.

3. " " " antenna.

4. " " mandible.

5. " " maxillule.

12.

(First and twelfth diagrams drawn according to scale I and others to scale II) 
region of this side. The third segment bears two spines, two setae and a single group of "comb row' of setae, all on the original outer lateral margin; the 'comb row 'is borne on the lateral half and the setae and spine on the apical half of this original outer lateral margin. The last segment of the antenna is the smallest with all the four sides clearly marked, held at right angle to the preceding segment and rather subrectangular and wider than long; this segment bears on its apical margin seven setae four of which are long and characteristically curved, while the other three are short and slender; one of these shorter setae is strongly ciliated on its inner margin.

All the four pairs of mouth appendages are present and they are closely compacted in typical poecilostome fashion. Mandible (Fig. VI, 4) is a small structure with the proximal half of its body proper much larger than the distal half; the latter bears two ciliated setae on its outer (in natural position rather directed posteriorwards) distal margin ; the terminal armature consists of a foliaceous flap fringed all along its borders with cilia and a broad rather conical spine which is serrated on both margins. Maxillule (Fig. VI, 5) is only as large as the mandible and is clearly bilobed towards the distal side; each lobe bears four setae, those on the inner appearing more like spines and much shorter; three of the longer setae are ciliated. Maxilla (Fig. VI, 6) is bimerous ; basal segment much inflated, bearing on its distal inner face a stout solitary seta which is ciliated on both margins. The armature of the distal segment is quite complex; in a lateral view the apex is Yshaped with asymmetrical limbs and a thick body; below this a seta is borne on each side, the one on the inner margin being ciliated and a little shorter than that on the outer margin; on the inner face between the seta and the base of the segment is borne a subrectangular structure which is denticulated on the apical margin. Maxilliped (Fig. VI, 7) is probably the most conservative structure. It is trimerous, first two segments being subequal and large and the third highly reduced. The basal segment is armed with two long setae and the second with an inner prominence carrying two spinous setae. The terminal segment bears two claws of unequal lengths and two short setae.

All the four pairs of swimming legs (Fig. VI, 8, 9, 10 and 11) are biramous and with two segmented protopods. The rami are all trimerous but the exopod is invariably shorter. The setal formula of the swimming legs is as follows:

\begin{tabular}{|c|c|c|c|c|c|c|c|c|c|c|c|c|c|c|c|c|c|}
\hline & \multicolumn{4}{|c|}{ Protopod } & \multicolumn{6}{|c|}{ Endopod } & \multicolumn{7}{|c|}{ Exopod } \\
\hline & \multicolumn{2}{|c|}{1} & \multicolumn{2}{|c|}{2} & \multicolumn{2}{|c|}{1} & \multicolumn{2}{|c|}{2} & \multicolumn{2}{|r|}{3} & \multicolumn{2}{|c|}{1} & \multicolumn{2}{|c|}{2} & \multicolumn{3}{|c|}{3} \\
\hline & $\mathbf{S i}$ & $\mathrm{Se}$ & $\mathbf{S i}$ & $\mathrm{Se}$ & $\mathrm{Si}$ & $\mathrm{Se}$ & $\mathrm{Si}$ & $\mathrm{Se}$ & $\mathrm{Si}$ & St $\quad S$ & $\mathbf{S i}$ & $\mathrm{Se}$ & Si & Se & $\mathbf{S i}$ & St & So \\
\hline $\mathbf{P}_{1}$ & $t$ & 0 & I & 1 & 1 & 0 & 1 & 0 & 4 & 1 & 0 & I & 1 & $I$ & 4 & I & III \\
\hline $\mathbf{P}_{2}$ & 1 & o & 0 & 1 & 1 & 0 & 2 & 0 & 3 & I I & 0 & I & 1 & I & 5 & I & III \\
\hline $\mathbf{P}_{3}$ & 1 & 0 & $\mathbf{0}$ & 1 & $\mathbf{1}$ & 0 & 2 & 0 & 2 & I II & 0 & I & 1 & I & 5 & I & III \\
\hline P. & 1 & 0 & 0 & I & 1 & 0 & 2 & 0 & 1 & I II & 0 & I & 1 & I & 5 & I & II \\
\hline
\end{tabular}

In the first leg the apical margin of the second protopod segment is uniformly ciliated. In the second and third legs the first protopod segment bears a group of three spinules on its outer distal margin and the second protopod segment, on its face between the exopod and endopod, a 'comb row' of spinules. In the fourth leg 
spinules on the first protopod segment are reduced to two; the second protopod segment bears, besides the 'comb row', two small spinules on its inner distal face. Fifth leg is 2-segmented and inserted on the ventro-lateral face of the first urosomal segment, one on each side. The proximal segment bears a single seta externally and is armed at the distal external angle with a row of fine spinules. The second is typical of the genus and more than twice as long as the first segment; it is much narrower at the base and is provided with spinules on both the outer and inner margins. It bears three rather conical broad based spines and a delicate seta between the second and third spines; the latter two spines may be termed apical in position while the first spine is sub-apical on the outer side.

Unknown.

B. Male

Remarks - Light and Hartman (1937) reviewed this genus and considered the following species as valid :

1. H. pugettensis Light and Hartman, 1937.

2. H. aberdonensis (Scott \& Scott), 1892.

3. H. adhaerens (Williams), 1907.

4. H. callianassae Wilson, 1935.

5. H. purpureus Boeck, 1873 .

6. H. thysonotus, Wilson, 1935 , and

7. H. americanus Wilson, 1932.

H. elongatus Wilson, 1937 was described in the same year as Light and Hartman's review and so was not included in their list. All these species were reported to occur along the American coasts except $H$. aberdonensis which was recorded only from Scottish seas. Gooding ( $l o c$. cit.) provided an excellent review of the American species of this genus and considered $H$. pugettensis and $H$. callianassae to be synonymous with $H$. thysonotus; and $H$. americanus as a synonym of $H$. adhaerens. He added two new species $H$. arenicola Gooding and $H$. subadhaerens Gooding to bring the total number of known American species again to six. $H$. purpureus has, however, been omitted from his key for he is not sure whether Wilson's identification of this species from the Canadian waters is correct in view of 'Wilson's lapses in descriptions of other species in this genus'.

The report of the occurrence of the species of this genus in other parts of the world is rather scanty. Besides the two American species referred to above, I am aware of the following species having been reported as belonging to this genus after Light and Hartman's review:

1. H. leggi (Thomp. \& Scott), 1903$)$

2. H. tamilensis $("), "$,

3. H. australis Nicholls, 1944

4. H. indicus Sewell, 1949

5. H. visendus, Humes, Cressey and Gooding, 1958

6. H. bacescui (Serban) 1956

7. H. dilatatus Shen and Bai, 1956
Both from Ceylon; transferred to this genus as suggested by Sewell, 1949

Australia

Nicobar Islands

Madagascar

Mediterrannean

China 
$H$. thompsoni Canu was kept in abeyance by Light and Hartman from the genus Hemicyclops because that species was based upon two immature females found on the body of Callianassa subterrannea Montagu. However both Stock (1959) and Humes, Cressey and Gooding (1958) have recognised this as a species of Hemicy. clops. There ate, therefore, fifteen species including the one described in this paper known in the genus Hemicyclops.

Gooding (loc. cit.) has pointed that four of the American species namely, adhaerens, subadhaerens, arenicolae and elongatus fall into a distinct group, more or less constituting a superspecies. "This superspecies would be characterised mainly by the separation between genital and first abdominal segments and the well-developed sixth legs in the adult females; the reduced mandibular setation and prisence only of simple terminal elements on the maxilla and of setulose exopod spines on all the swimming legs in both sexes; and the attenuated 'scaly' tip of the male maxilliped' (p. 164). To this superspecies-complex should probably be added H. tamilensis for in this species also the genital and the first abdominal segments are completely free. However, we have no information about the various appendages which are of systematic importance. $H$. indicus and $H$. dilatatus are separated from others easily by the subquadrate nature of the genital segment which is followed by three abdominal segments. In $H$. leggi only the male is known and the possibility or otherwise that the present example represents the unknown female of that species is discussed later (vide infra).

In the remaining seven species the genital segment is quite elongate with a broader anterior and a narrower posterior regions and there are three post-genital segments. However, in bacescui, visendus, thompsoni and thysonotus the caudal ramus is distinctly long, always more than twice as long as wide and are easily distinguished from purpureus, australis and the present species, all of which have their caudal rami sub-quadrate.

$H$. intermedius sp. nov. is not referred to $H$. purpureus because of the following differences:

\section{H. intermedius}

1. The exopod of first leg has four setae and four spines.

2. Relative lengths of the antennular segments :

$$
\begin{aligned}
13.8 ; 10.6 ; 11.2 ; 22.4 ; 15.2 ; 13.4 ; \\
13.4=100
\end{aligned}
$$

3. The antennal segments are bent twice forming an inverted ' $U$ '-tube.

4. Caudal ramus as Jong as wide.

5. The basal segment of maxilla with one seta. The distal segment as described.

6. Terminal segment of maxilliped bears limited number of setae and spines.

7. Length of female $1,9 \mathrm{~mm}$.

\section{H. purpureus}

The exopod of first leg has two spines and six setae.

Relative lengths of the antennular segments :

$10.0 ; 23.2 ; 9.4 ; 18.8 ; 13.5 ; 14.1 ; 11.0=100$

The first segment is bent at right angles to tho next three segments which are linear.

Caudal ramus slightly longer than wide.

Basal segment of maxilla with two setae. The distal segment simpler in structure.

Terminal maxilliped segment bears four setae and two spines.

Length of female $1.15 \mathrm{~mm}$. 
The present species is related to $H$. australis but the following differences are noticeable between the two species:

H. australis

1. Size : $1.38-1.40 \mathrm{~mm}$.

2. Prosome: Urosome $=53: 47$

3. Proximal half of genital segment more than one and a half times wider than the distal half.

4. The genital segment longer than the three abdominal segments combined.

5. Caudal ramus longer than the last abdominal segment.

6. Third antennular segment much shorter than the second.

7. In the mandible, the body proper bears a single seta on its distal inner margin.

8. In the first leg the terminal exopod seg. ment carries six setae and two spines.

\section{$\boldsymbol{H}$, intermedius}

$1.9 \mathrm{~mm}$.

Prosome : Urosome $=51: 49$

Proximal half of genital segment only a little wider than the distal half.

The genital segment only as long as the three abdominal segments combined.

Caudal ramus not as long as the last abdominal segment.

Third antennular segment as long as the second.

In the mandible the body proper bears two setae on its distal inner margin.

In the first leg the terminal exopod segment carries four setae and four spines.

$H$. leggi was created by Thompson \& Scott (loc. cit.) from the Ceylon side of the Gulf of Mannar and was referred to the genus Hersiliodes Canu. Sewell (loc. cit.) suggested its removal to the genus Hemicyclops. The single male specimen which they obtained from sponge washings measured only $1.5 \mathrm{~mm}$. Taking into consideration this size difference of the male of $H$. leggi and the female of $H$. intermedius as well as the same area of the distribution (hardly $\mathbf{5 0}$ miles apart) of the two species, one is tempted to suggest that they represent the male and the female of the same species. However a number of difficulties come in the way. Although the male is generally smaller in size than the female in many of the species of the genus, this condition is never the rule, for in $H$. visendus it is clearly larger than the female : the male measures $2.06 \mathrm{~mm}$. while the female is only $1.87 \mathrm{~mm}$. long. However, in this genus the male is known to differ from the female only in the structure of the maxilliped and the urosome. The differences observed in other structural details are considered of specific importance. Such characters are listed below :

(a) The proportionate lengths of the antennular segments are distinctly different in the two species.

$\begin{array}{lcccccccc} & 1 & 2 & 3 & 4 & 5 & 6 & 7 & \\ \text { H. leggi } & 13.0 & 16.0 & 8.5 & 23.0 & 15.0 & 10.5 & 14.0=100 \\ \text { H. infermedits } & 14.5 & 10.6 & 10.7 & 22.0 & 15.5 & 13.35 & 13.35=100\end{array}$

(b) First segment of the antenna in $H$. leggi is bent at right angles to the remainder of the appendage ; in $H$. intermedius the antenna is bent twice on itself forming an inverted U-tube with the first and the last segments forming the two limbs and the middle segments forming the base. Further the setation of the constituent segments is also different in the two species, 
(c) In the maxilla of $H$. intermedius the basal segment bears only a single seta on its distal inner margin, while two distinct setae are borne in $H$. leggi; further the segment itself is very short in $H$. leggi.

(d) The terminal endopod segment of first leg bears five setae and one spine in the present species whereas for $H$. leggi it is shown to be only four setac and one spine.

(e) The length-breadth ratio of the fifth leg in $H$. leggi is $3: 2$ while it is $2: 1$ in H. intermedius. Since Thompson \& Scott (loc. cit.) themselves have pointed that their species "is easily recognized from any other members of the genus by the proportionate lengths of the joints of the anterior antennae and by the quidrangular fifth leg ', I consider the present form as a new species.

\section{Family LICHOMOLGIDAE SARS}

Sars, 1918 , p. 149.

\section{Sub-family LichOMOLGINAE GURNEY}

Gurney, 1927, p. 463.

Genus Pseudoanthessius Canu

Canu, 1889, p. 344.

Sars, 1918, p. 166.

Pseudoanthessius agilis sp. nov.

Material examined-Numerous males and females of this copepod were captured from the sponge washings from the Gulf of Mannar in July and Atgust 1960. On one occasion it was obtained from general invertebrate and weed washings (which of course included sponges). The holotype, allotype, and paratypes are deposited in the Central Marine Fisheries Research Institute and bear the registered numbers $\mathrm{J} 576 / 9, \mathrm{~J} 577 / 9$, and $\mathrm{J} 578 / 9$ respectively.

\section{Description : $\quad$ A. Female}

Colour is monotonously whitish opaque ; but the edges of the different segments possess a beautiful tinge of violet which appears to be due to the deposit of calcium. The body (Fig. VII, 1) is very graceful in appearance, quite symmetrical and almost cylindrical. The prosome consists of four segments and the urosome of five segments. The first prosomal segment is, however, partially divided into the cephalosome and the first leg-bearing segment. The cephalothorax is the widest part of the body, being almost three times wider than the last prosomal segment. In length the cephalothorax is twice as long as that of the three following segments combined. The matasomal segments gradually diminish in width posteriorly. All the segments excepting the last prosomal segment are provided with epimeral plates. There is a clear rostral prominence on the anterior margin of the first prosomal segment. In the urosome the first segment bears the fifth pair of legs which are typically reduced. The genital segment forms a major part : it is much longer and wider than the other segments joined together and carries on each side a small spine on 


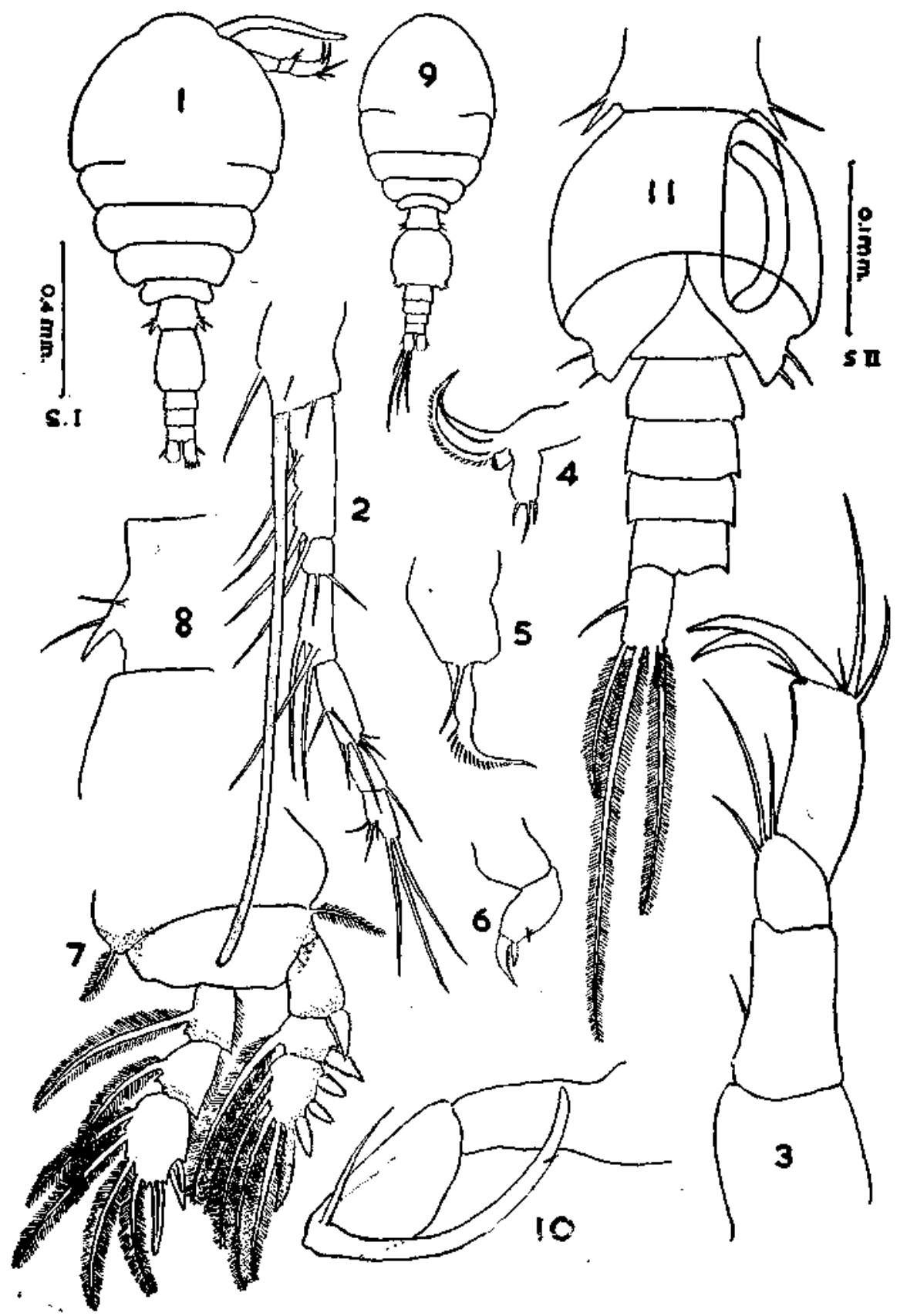

Figure VII, 1-11. Pseudoanthessius agilis sp. nov.

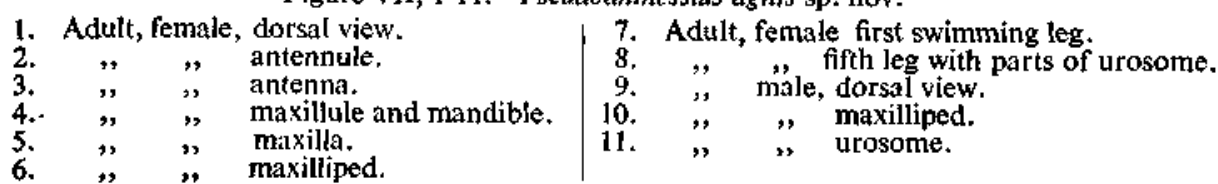

(First and nintb diagrams are drawn to scale I and others to scale II 
its postero-lateral margin. First, second and third abdominal segments are subequal in length but diminish in width posteriorly. Caudal rami are parallel, distinctly exceeding the last abdominal segment in length and a little less than twice as long as wide. Each of them bears four terminal setae and a small spine on the outer margin at its mid-length.

Antennule (Fig. VII, 2) is moderately long, reaching when extended posteriorly to the end of the cephalosome. It is 7-segmented and the segments have the following relative lengths :

$\begin{array}{llllllll}1 & 2 & 3 & 4 & 5 & 6 & 7 \\ 19.6 & 24.8 & 6.0 & 15.7 & 13.9 & 10.0 & 10.0=100\end{array}$

The second segment is the largest and the third the shortest. Fourth and fifth segments are approximately of equal length; so also are the last two segm:nts. The first segment is fairly stout and long and bears an aesthetask equal in length to that of the entire antennule. All the segments are provided with a number of selae. The antenna is well-developed and consists of four segments. First segment is devoid of any seta. The third segment bears three setae, of unequal length on its inner anterior distal margin. The last segment bears four setae of varying lengths and two stout spines; the latter are characleristically bent to the anterior side. The mandible (Fig. VII, 4) as usual, is a flat blade, produced into an elongale, tapering tip which curves outwards. The entire inner margin is lined by minute spinules. A broad, rather rectangular, chitinized flap is present near the inner base of the blade. It is tipped with fine spinules. The base of the mandible is closely associated with the base of the maxillule and are mounted on the same skeletal frame work. Maxillule (Fig. VII, 4) is simple, rather rectangular in shape, bearing three spines of unequal length on the apical margin. In the maxilla (Fig. VII, 5) the basal segment is quite pronounced and bears a seta besides the apical lash ; the latter is moderately long, bent at about right angles in the distal part and bearing along its entire length slender spinules which diminish in length distalwards. The maxilliped (Fig. VII, 6) consists of two segments, the basal is the wider, but the distal is the longer; the latter bears two serrated spines at the apex and a small spinule at about two-third length. Maxilliped is rather feeble.

The swimming feet (Fig. VIr, 7 ; Fig, VIII, 1,2 and 3) are biramous, the ramus being three-segmented, except in the case of the endopod of the fourth lig which is only one-segmented. The legs are notable in that the corners and edges of the various segments are highly calcified and have a dark violet tinge. The selal formula of the swimming legs are as follows :-

\begin{tabular}{|c|c|c|c|c|c|c|c|c|c|c|c|c|c|c|c|c|c|}
\hline & \multicolumn{4}{|c|}{ Protopod } & \multicolumn{7}{|c|}{ Endopod } & \multicolumn{6}{|c|}{ Exopod } \\
\hline & \multicolumn{2}{|c|}{1} & \multicolumn{2}{|c|}{2} & \multicolumn{2}{|r|}{1} & \multicolumn{2}{|c|}{2} & \multicolumn{3}{|c|}{3} & \multicolumn{2}{|c|}{1} & \multicolumn{2}{|c|}{2} & \multicolumn{2}{|r|}{3} \\
\hline & $\mathrm{Si}$ & Se & $\mathrm{Si}$ & & $\mathrm{Si}$ & Se & $\mathbf{S i}$ & $\mathrm{Se}$ & $\mathbf{S i}$ & $\mathrm{St}$ & $\mathrm{Se}$ & $\mathrm{Si}$ & Se & $\mathrm{Si}$ & $\mathrm{Se}$ & $\mathrm{Si}$ & St Se \\
\hline $\mathbf{P}_{\mathbf{z}}$ & 1 & 0 & 0 & 1 & 1 & 0 & 1 & 0 & 4 & I & I & 0 & I & 1 & I & 4 & I III \\
\hline $\mathbf{P}_{2}$ & 1 & 0 & 0 & 1 & 1 & 0 & 2 & 0 & 3 & II & $I$ & 0 & I & 1 & I & 5 & I III \\
\hline $\mathbf{P}_{3}$ & 1 & 0 & 0 & 1 & 1 & 0 & 2 & 0 & 2 & II & I & 0 & I & 1 & I & 5 & I Ш \\
\hline P. & 0 & 0 & 0 & 1 & & & I & & & & & 0 & $l$ & 1 & I & $s$ & I II \\
\hline
\end{tabular}


First leg is the smallest. Second and third legs are similar except for the differences in the setation of the terminal segment of the endopod. In the fourth leg the reduced endopod is half as long as the exopod and its margins are entire. The fifth pair of legs, as in other species of the genus, are replaced on each side by a spine inserted directly to the postero-lateral margin of the first urosomal segment and accompanied by two small setae; the spine is smooth, exhibiting at the base a slight dilation and is directed posteriorwards. One of the setae arises just close to the spine and the other a little upwards. The size of the female is $1.18 \mathrm{~mm}$.

\section{B. MALE}

The male (Fig. VII, 9) is much smaller than the female, displaying the usual sexual differences. The prosome is more oval and compact than in the female and the first and the second prosomal segments only partly fused. The urosome (Fig. VII, 11) is 6-segmented. The genital segment is very much widened, almost as wide as long and uniform throughout the length. At the postero-lateral corners the segment becomes constricted to a bud-like structure, each of which bears two fine spines. The four abdominal segments diminish both in length and width to the posterior side. The caudal rami and setae are similar to those of the female. The maxilliped (Fig. VII, 10) is very large and prehensile, many times longer than the corresponding structure of the female. It consists, however, of the same two segments which are subequal in length. The terminal spine of the second segment is extremely large, characteristically bent inward and bears a small spine on its distal posterior margin. There is also a seta close to the base of the terminal spine. The mouth parts as well as other remaining appendages are identical to those of the female.

Remarks-A number of species that were originally attributed to this genus have been recorded from Indian waters but several of these have subsequently been transferred to other genera.

Nicholls (loc. cit.) provided an excellent key to the genus and enlisted the follow* ing species as known to the time of his writing :

1. P. liber, (Brady \& Robertson), 1875.

2. P. assimilis Sars, 1917.

3. P. sauvagei Canu, 1891 .

4. P. obscurus A. Scott, 1909.

5. P. mucronatus, Gurney, 1927.

6. P. tenuis Nicholls, 1944.

7. P. gracilis Claus, 1889.

8. P. weberi A. Scott, 1909.

9. P. nemertophilus Gallien, 1935.

10. P. thorelli (Brady \& Robertson), 1875.

11. P. dubius Sars, 1918.

12. P. concinnus Thompson \& Scott, 1903.

Illg (1950) revised the key incorporating three more species, $P$. spinifer Lindberg, 1946, $P$. graciloides Sewell, 1949 and $P$. latus Illg, 1950 that have since then been added. The present species brings the total number of known numbers of this 
genus to sixteen. The species of this genus are divisible into two groups; those in which the outer margin of the fourth endopod is entire or is simply convex ; and those in which the outer margin of the fourth endopod is broken by a swelling or indentation which may become a conspicuous knob or notch. P. spinifer, $P$. liber, $P$. assimilis and the present species fall under the first group. $P$. spinifer, however, is easily separated by the fact that the lateral margins of the genital segment of this species are produced into conspicuous expansions. The distinctions between $P$. liber and $\boldsymbol{P}$. assimilis on the one hand and $\boldsymbol{P}$. agilis sp. nov. on the other are many, and the most important of them consists of : $(a)$ the general shape of the body; (b) the nature of the fusion of the first and second prosomal segments ; $(c)$ the proportionate lengths of the segments of the antennule; $(d)$ the proportionate lengths of the segments and the size of the terminal spines of the antenna; and (e) the number of setae borne on the inner margin of the third segment of the third leg. The differences between $\boldsymbol{P}$. liber and $P$. assimilis have already been pointed out by Nicholls and consists chiefly the length-width relationship of the caudal rami and in the general form of the body.

Genus Macrochiron BRADY

Brady, 1872, p. 433.

Sars, 1913-18, p. 163.

Subgenus Macrochiron SEWELL

Sewell, 1949, p. 99.

Macrochiron (Macrochiron) rigida sp. nov.

Material examined-Eight females and three males were obtained from the general weed and invertebrate washings mainly sponges from the Gulf of Mannar. The holotype, allotype and the paratypes are deposited in the Central Marine Fisheries Research Institute, Mandapam Camp and bear the registered numbers J 616/10, $\mathrm{J} 617 / 10$ and $\mathrm{J} 618 / 10$ respectively.

\section{Description : $\quad$ A. Female}

The body (Fig. IX, 6) is moderately slender and cylindrical with the prosome not much dilated, being regularly oblong-oval in outline and rather strongly vaulted dorsally. The prosome is 4-segmented and the urosome 5-segmented. The first prosomal segment constitutes the major part of the body being only a little less than equal in length to the entire remainder of the body; it is also the widest of all segments. Second, third and fourth segments diminish in width posteriorwards. Of these, second is the longest and third the shortest. The first urosomal segment is moderately large and bears the fifth pair of legs. The genital segment is the largest urosomal segment, being distinctly wider and Jonger than the combined length of the three abdominal segments. The caudal ramus is as long as the last abdominal segment and is slightly longer than broad. Each ramus bears six setae, two of them being slender, looking more like spines. 
48 A. N. P. UMMERKUTTY

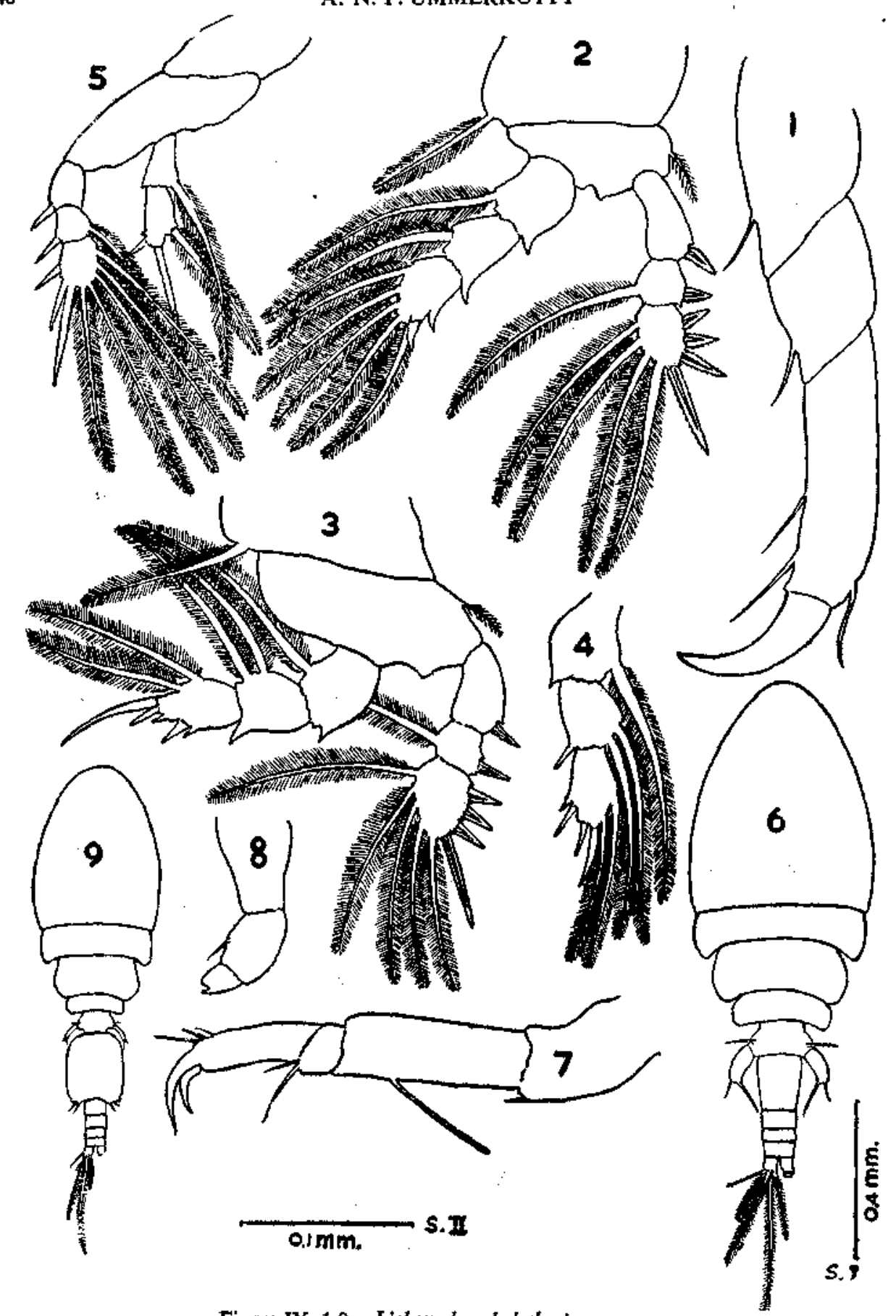

Figure IX, 1-9. Lichomolgus holothuriae sp, nov.

1. Adult, female antenna. 4. Adult, female, endopod of third swimming leg.

2. " " furst swimming leg. 5. " " fourth swimming leg.

Macrochiron (Macrochiron) rigida sp. nov.

$\begin{array}{ll}\text { 6. Adult female, dorsal view. } & \text { 8. Adult, female, maxilliped, } \\ \text { 7. " } & \text { 9. " male, dorsal view. }\end{array}$

(Sixth and ninth diagrams drawn according to scale I and others according to scale II) 
Antennule (Fig. X, 1) is 7-segmented, and rather not very long. Second segment is the largest and last the shortest. All the segments are provided with a number of setae ; first segment also carries a small finger-shaped structure on its anterior distal corner; two fairly long aesthetasks are borne, one each by the fifth and seventh segments. The proportionate lengths of the antennular segments are given below :

$\begin{array}{cccccccc}1 & 2 & 3 & 4 & 5 & 6 & 7 & \\ 14.6 & 22.7 & 9.6 & 18.3 & 14.6 & 11.7 & 8.5 & =100\end{array}$

Antenna (Fig. IX, 7) is comparatively short and consists, as usual, of four segments. Second segment is the largest and third the shortest while the first and the last are subequal in between these two extreme situations. Although the second segment of the antenna in this genus usually bears a spine, in the present case it is found to be a sensory filament rather than a spine. Other cephalosomal appendages are quite normal.

The four pairs of swimming legs $(\mathrm{X}, 3,4,5 \& 6)$ are biramous, each ramus being 3-segmented, except the fourth endopod which is 2-segmented. First to third legs are more or less of equal size while the fourth is distinctly smaller ; in the latter, although the endopod is only 2 -segmented, it is only a little less than the length of the exopod. The setal formula of the four pairs of the swimming legs are given below :

\begin{tabular}{|c|c|c|c|c|c|c|c|c|c|c|c|c|c|c|c|c|c|}
\hline & \multicolumn{4}{|c|}{ Protopod } & \multicolumn{7}{|c|}{ Endopod } & \multicolumn{6}{|c|}{ Exopod } \\
\hline & & & 2 & & & & 2 & & & 3 & & . & & & & 3 & \\
\hline & $\mathbf{S i}$ & Se & $\mathrm{Si}$ & Se & $\mathbf{S i}$ & $\mathrm{Se}$ & $\mathbf{S i}$ & Se & $\mathrm{Si}$ & St & Se & $\mathbf{S i}$ & Se & $\mathrm{Si}$ & Se & $\begin{array}{ll}\mathrm{Si} & \mathbf{S t}\end{array}$ & Se \\
\hline $\mathbf{P}_{\mathbf{1}}$ & 1 & 0 & 0 & 1 & 1 & 0 & 1 & 0 & 4 & I & I & 0 & I & 1 & I & $3 i+I$ & III \\
\hline$P_{2}$ & 1 & 0 & 0 & 0 & 1 & 0 & 2 & 0 & 3 & II & $\boldsymbol{I}$ & 0 & I & 1 & I & $5 \mathrm{I}$ & III \\
\hline$P_{3}$ & 1 & 0 & 0 & 0 & 1 & 0 & 2 & 0 & 2 & II & I & 0 & I & 1 & I & $5 \mathrm{I}$ & III \\
\hline$P_{s}$ & 0 & 0 & 0 & I & 1 & 0 & - & 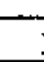 & & & & 0 & I & 1 & I & 51 & III \\
\hline
\end{tabular}

Fifth leg is cylindrical and fairly large, reaching more than half the lengths of the genital segment. The basal segment, as usual, is fused, with the first urosomal segment and each bears a solitary seta at its distal outer corner. The distal segment is slightly curved inwards and bears two terminal setae of unequal length. The size of the female is $1.25 \mathrm{~mm}$.

\section{B. MALE}

The male (Fig. IX, 9) is much smaller than the female but retain the general form of the female. The prosome is greatly identical in both shape and proportionate lengths of different segments. The urosome is 6-segmented, consisting of the fifth leg-bearing segment, the genital segment and four abdominal segments. Of these, the first segment is comparable to that of the female and bears the fifth legs which are much reduced in size. The genital segment is greatly enlarged both in length and width. It is almost equivalent to the combined length of the other 


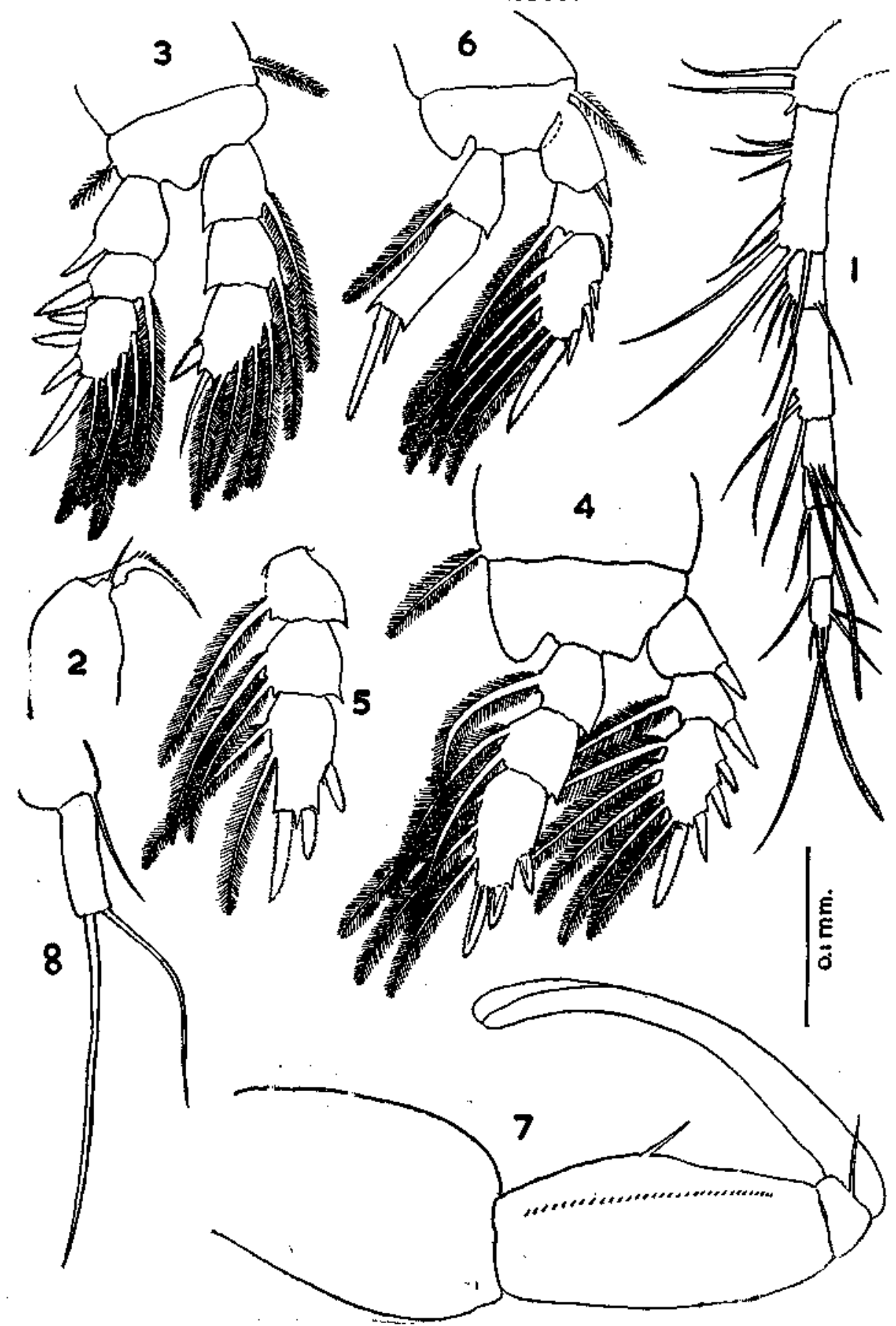

Figure X, 1-8. Macrochiron (Macrochiron) rigida sp. nov.

1. Adult, female, antenna.
3. " $"$ maxilla.

7. Adult, male, maxilliped. $\quad$ Lichomolgus brevifurcata sp. novi.
| 8. Adult, female, fifth leq. 
urosomal segments; at its posterior margin it bears, on either side, a pair of spines which are directed postero-laterally. The abdominal segments diminish both in length and width to the posterior side. The length of the male is $1.0 \mathrm{~mm}$. The maxilliped is quite large, similar to that of the related species and exhibiting sexual dimorphism. The fifth legs are much smaller in size and are also slender although in essential features they are similar to those of the female. The two segments of the fifth leg bear the same number of setae as in the female.

Remarks: Sewell (loc. cit.) has split the genus Macrochiron Brady into two subgenera, Macrochiron (Macrochiron) to receive all those species in which the endopod of the fourth leg is composed of two segments, as in the case of the type species, M. fucicolum Brady and Macrochiron (Paramacrochiron) to include those species in which the fourth endopod is only 1-segmented. He attributed the following species to the subgenus Macrochiron (Macrochiron) Sewell.

1. M. (Macrochiron) fucicolum Brady.

2. $M . \quad$ " hirsutipes (T. Scott).

3. M. " alabatensis (Kossman) (=Lichomolgus alabatensis)

4. $M . \quad$ " simplex (Thom. \& Scott) $(=$ L. simplex)

5. M. " buddhensis ( " ) (=Lichomolgus buddhensis)

6. $M . \quad$, robustus ( , $)(=L$, robustus $)$

7. M. " $\quad$ gracilipes (A. Scott) $(=$ L. gracilipes)

8. M. , congoensis (T. Scott $)(=L$. congoensis $)$

9. $M . \quad$ " longipes Sewell

10. $M . \quad$ " spinipes Sewell

The present species does not correspond to any of the known forms and therefore is treated here as a new species. $M$. (Macrochiron) rigida may be defined as follows : (1) Length of the female $1.25 \mathrm{~mm}$. ; length of the male $1.0 \mathrm{~mm}$. (2) the cephalosome and first pedigerous segment are fused and the combined cephalothorax is only a little less long than the entire rest of the body. (3) The posterior half of the cephalothorax is the widest part of the body. (4) The genital segment in the female is vase-like, the proximal wider part gradually but slightly diminishing in width to the posterior side ; it is distinctly longer and wider than the three abdominal segments together. In the male the genital segment is rather rectangular with parallel sides ; it is almost as long as the entire remainder of the urosome; there is a pair of postero-laterally directed spines on either of its posterior margins. (5) Caudal ramus as long as the last abdominal segment and is longer than wide. (6) The proportionate lengths of the antennular segments and the setal formula of the swimming legs are as given in the text. (7) The fifth pair of legs stout, incurved, rather cylindrical and wider in the proximal half; the male fifth legs are highly reduced.

Recently Stock (1957) expressed the opinion that the name Macrochiron should be used at generic level for the conception of a limited number of species all agreeing in the possession of a complexly built 3-segmented posterior antenna. According to him, all other species that have been referred to this genus but in which there is a normally built 4-segmented posterior antenna should be removed to the genus $\mathrm{Lic}$ homolgus or other related genera. Those transferred to Lichomolgus differ, however, from the typical members of the genus in a number of characters: (1) The mandibles have the lappet conspicuously dilated at the base. Its armature consists not only of spinules lining the margin but also of crest-like ridges, denticulations, etc. 
(2) The maxillipeds of the female are well-developed, three-segmented, with at least two setae on the second segment and a cheliform structure on the third segment. (3) The third exopod segment of the fourth leg has usually three outer spines, though some species have two outer spines.

To accommodate this rather natural group of uncertain systematic status within the genus Lichomolgus, Stock (1959) proposed to erect a new subgenus, but left it unnamed, 'since no name is available at the moment for the subgenus and since some species tend to be intermediate. ...'

If Stock's suggestions are accepted and Macrochiron is redefined as proposed by him, then the present species should be transferred to Lichomolgus and placed under the subgenus proposed by him.

\section{Genus Lichomolgus THORELL}

Canu, 1892, p. 227

Sars, 1918, p. 150

Sewell, 1949, p. 96

\section{Lichomolgus holothuriae sp. nov.}

Material examined-Numerous females and a few males were obtained from the holothurian washings of the Gulf of Mannar. They live inside the body cavity of the holothurians and are obtained by keeping the host in seawater to which menthol is added. The copepods are brought out by vigorously shaking the host after the interval of an hour or so. In colour they are dull whitish approaching to a pale yellow. The holotype, the allotype and the paratypes are deposited in the Central Marine Fisheries Research Institute and have the registered numbers $\mathrm{J} 628 / 11, \mathrm{~J} 629 / 11$ and $\mathrm{J} 630 / 11$ respectively.

\section{Description: A. Female}

The body (Fig. VIII, 4) is highly depressed, flattened and more or less oval in outline. The prosome consists of four segments. The first prosomal segment is eminently large, only a little less than the combined length of the rest of the body. Its posterior corners end in angular edges. There is no trace of division between cephalosome and first leg-bearing segment. Second and third segments are moderately large but much smaller than the first prosomal segment. They are provided with epimeral plates and have angular posterior edges. The last prosomal segment is quite small, less than one-third of the width of the prosomal segment and about one-ninth of the latter's length. It is partly hidden by the preceding segment. The four prosomal segments bear the four pairs of swimming legs. The urosome is 5 -segmented, consisting of the fifth leg-bearing segment, the genital segment and three abdominal segments. The first two segments are very large, subequal each distinctly longer than the combined lengths of the three abdominal segments. In width the genital segment exceeds all other segments of the urosome. It bears a pair of spines on either of its postero-lateral margins; one of the spines is much larger than the other and is borne on a protrusion. The caudal rami are very short, 


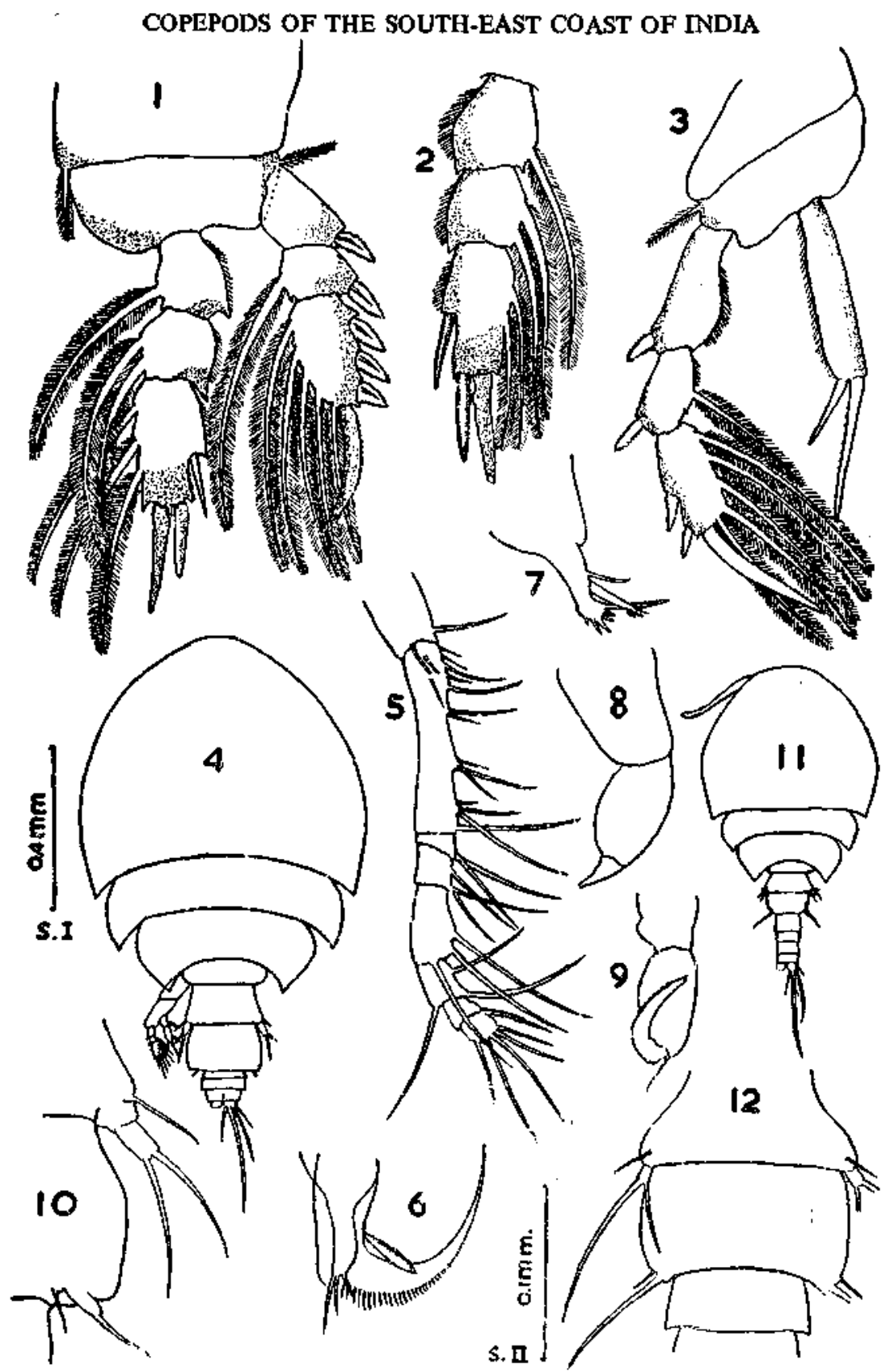

Figure VII, 1-12. Pseudoanthessius aglis sp. nov.

1. Adult, female, second swimming leg.

2. " " endopod of third swimming leg.

Lichomolgus holothuriae sp, nov,

4. Adult, female, dorsal view.

5. Adult, female, dorsal view.

6. " " " mandible and maxillule.

7. maxilla.

8. " " " maxilliped.

(Fourth and eleventh diagrams are drawn according to scale I and others according to scale II) 
stumpy, much wider than long, the length-width ratio being $5: 3$. Each of the rami bears five setae, one of which is clearly long, almost equivalent to the urosome.

Antennule (Fig. VIII, 5) is 8-segmented, typically of the lichomolgid type with the second segment being the largest and third the shortest. First and fifth segments are fairly large but each of them is less than half the length of the second segment. While the fourth and fifth segments are longer than wide, the reverse is true of the last two segments. All the segments are provided with a number of setae, some of them appearing more like spines. The antennule does not bear any aesthetask. The relative lengths of the various segments are as follows :

$\begin{array}{rcccccccc}1 . & 2 & 3 & 4 & 5 & 6 & 7 & 8 \\ 13.0 & 40.2 & 2.6 & 7.4 & 17.0 & 8.9 & 5.3 & 5.6=100 .\end{array}$

Antenna (Fig. IX, 1) is very large in size compared to the antennule. While the latter hardly reaches the middle of the first prosomal segment and is fragile, the antenna is stoutly built and extends to more than three-fourth the length of that segment. However, it is only three-segmented. The first two segments are subequal, while the third is quite large and almost as large as the former two combined. The two segments bear a seta each. The third segment bears three setae and a stout terminal spine which is half the length of the segment itself. The spine is incurved like a beak. The mandible (Fig. Vill, 6) is distinct from the maxillule and juxtaposed to it. It consists of a blade with its anterior (outer) margin lined by fine long spinules which decrease in length distalwards. At the base of the posterior (inner) margin of this blade, there is an oblique ridge with fine cilia on one of its margins. The blade is produced into a flagellum. The maxillule (Fig. VIII, 6) is rather small, elongated and bearing terminally three spines. The maxilla (Fig. VIII, 7) is rigid. It has two separate spines besides the terminal lash which is denticulated ; while the proximal spine is simple, the distal one is stout and has its tip provided with small denticles; the distal part of the apical lash is much slender than in all other known species and is rather straight, being ciliated on the inner margin. The basal part of the lash is distinct and is provided with stout but small spinules instead of the usual setae. Maxilliped (Fig. VIII, 8) is simple and small. It consists of two segments of approximately equal length and width. The distal segment bears a seta and a terminal claw which is conical and rather small.

The first three pairs of swimming legs (Fig. IX, 2, 3, 4 \& 5) are biramous, each ramus being trimerous. The legs are approximately of equal size but differs in setation. In all the legs, while the exopod is orientated in the same axis as the protopod, the endopod is borne at an angle; in the case of third legs exactly at right angles to the protopod. The fourth leg is biramous. The exopod is 3-segmented; the endopod is only 2-segmented. The fourth leg is much smaller than the other legs. The setal formula of the swimming legs are as follows :

\begin{tabular}{|c|c|c|c|c|c|c|c|c|c|c|c|c|c|c|c|c|c|c|}
\hline & \multicolumn{4}{|c|}{ Protopod } & \multicolumn{7}{|c|}{ Endopod } & \multicolumn{7}{|c|}{ Exopod } \\
\hline & & & & 2 & & 1 & & 2 & & 3 & & & 1 & & 2 & & 3 & \\
\hline & Si & Se & Si & $\mathrm{Se}$ & $\mathrm{Si}$ & Se & $\mathrm{Si}$ & $\mathrm{Se}$ & $\mathrm{Si}$ & St & Se & $\mathrm{Si}$ & Se & $\mathbf{S i}$ & $\mathrm{Se}$ & Si & $\mathbf{S t}$ & $\mathrm{Se}$ \\
\hline $\mathbf{P}_{\mathbf{x}}$ & 1 & 0 & 0 & 1 & 1 & 0 & 1 & 0 & 4 & 1 & I & 0 & I & 1 & I & 4 & I & III \\
\hline $\mathbf{P}_{*}$ & 1 & 0 & 0 & 1 & 1 & 0 & 2 & 0 & 2 & II & I & 0 & I & 1 & $\mathbf{r}$ & 4 & $1+I$ & III \\
\hline $\mathbf{P}_{\mathbf{z}}$ & 1 & 0 & 0 & 1 & 1 & 0 & 2 & 0 & 2 & I & II & 0 & I & 1 & I & 4 & $1+I$ & шI \\
\hline $\mathbf{P}_{*}$ & $\mathbf{0}$ & 0 & 0 & 0 & 1 & 0 & 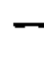 & 1 & & II & & 0 & I & 1 & I & 4 & $1+I$ & II \\
\hline
\end{tabular}


Fifth leg (Fig. VIII, 10) is 2-segmented, the basal segment being fused with the first urosomal segment and bearing a single seta ; the second segment is well defined and fairly large; it bears two terminal setae of unequal size. The size of the finnale is $1.2 \mathrm{~mm}$.

\section{B. MALE}

The male (Fig. VIII, I1) is much smaller than the female measuring only $0.75 \mathrm{~mm}$. The prosome is very similar to that of female except in size. The urosome is composed of six segments. The first two segments are subequal in length and width. The second segment bears on each of its postero-lateral corners a fairly long spine which is said to be the remains of the sixth pair of legs. The four abdominal segments are much narrower and form a cylinder ; of these, the third to fifth segments are more or less of equal dimensions while the second abdominal segment is distinctly longer and wider. All the appendages are similar to those of the female except the maxilliped (Fig. VIII, 9) which is very peculiar. In the males of the lichomolgids the maxilliped is generally well developed being many times larger than that of the female. It is supposed to have a geniculate function. In the present species the male maxilliped exhibits some differences in the structure from that of the female but is hardly larger. In both cases it is 2 -segmented. In the fomale the two segments are sub-equal and the terminal spine of the second segment is very small. In the male, however, the second segment is larger and the terminal spine of that segment is quite large. Further the outer margin of the spine is partly serrated.

\section{Lichomolgus serratipes sp. nov.}

Material examined. Eighteen female specimens were obtained from washings of the seapen Pteroides esperi Herklots; the specimens were given to me by Dr. S. Jones. Some of these were carrying egg-sacs which were asymmetrical and which appeared to have started hatching. The left egg sac is always longer and contains a larger number of eggs than the right one. The holotype and the paratypes are deposited in the Central Marine Fisheries Research Institute and bear the registered numbers $\mathrm{J} 658 / 12$ and $\mathrm{J} 659 / 12$ respectively.

\section{Description :}

A. Female

The animal (Fig. XIII, 5) is very robust and rather elongate-oval. The prosome is very conspicuous, constituting as it does, more than four-fifth of the length of the body. It consists of four segments : The first segment is quite large, equal in length to the entire remainder of the body. This segment is considerably expanded and much broader than the succeeding ones; its posterior margin is concave so that the postero-lateral corners constitute acute angles. The second segment is distinctly less wide than the first one and is crescent-like with arms directed backwards. The third segment is less broad than the preceding one but exceeds the latter in length, the medial line being the longest part. The postero-lateral margins of this segment are finely serrated. The fourth segment is very small, a little wider than the genital segment and completely hidden by the preceding segment in formalin preserved specimens. The postero-lateral margin of this segment also is finely serrated and the specific name of the species has reference to this character. The urosome is 5-segmented (Fig. XIV, 4) but is very small compared to the size of the prosome. The pre-genital segment is rather small and bears the fifth pair of legs. In length it is only one-third of the genital segment, but it exceeds the latter in breadth. The genital segment is stumpy, much broader than long and without 


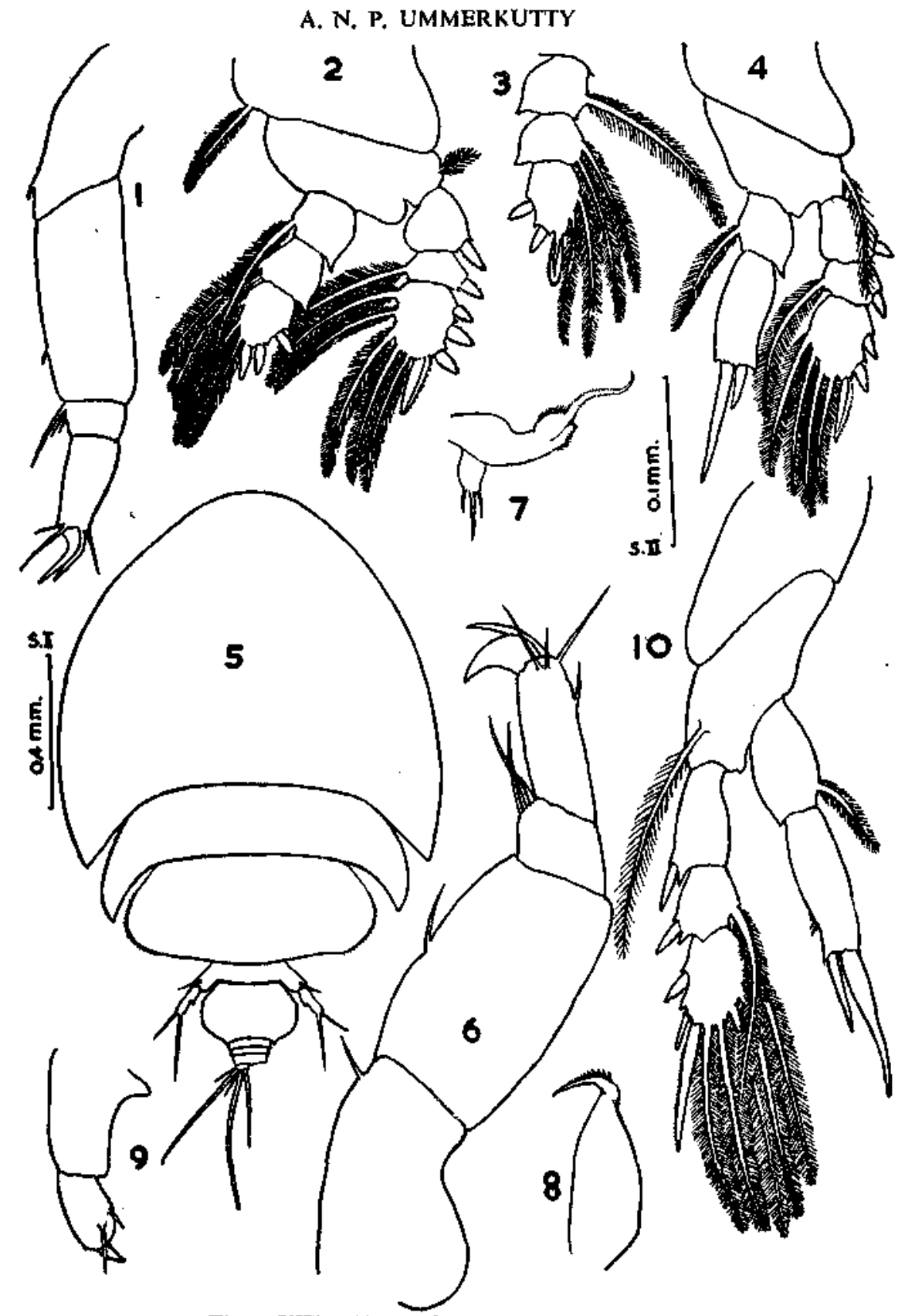

Figure XIII, 1-10, Lichomolgus indicus sp. nov.

\begin{tabular}{l|l} 
1. Adult, female, antenna. & 3.
\end{tabular}, " endopod of third swimming leg.

2. " " second swimming leg. 4. ", ", fourth swimming leg.

5. Adult, female, dorsal view. Lichomolgus serratipes sp. nov.

8. Adult, female, maxilla.

6. " " antenna. 9 9. Adult, female, maxilliped.

7. " " maxillule and mandible. 10. ", " fourth swimming leg.

(Diagrams I and 5 are drawn according to scale I and others according to scale II) 
any accessory spine or seta. The three abdominal segments are very inconspicuous and crowded together behind the genital segment. They are subequal in length but decrease gradually in breadth to the posterior side. The last segment bears the caudal rami which are distinctly wider than long. Each of the rami bears five setae, the second one from the inner side being the longest.

The antennule (Fig. XIV, 3) consists of eight segments which bear the following proportionate lengths :

$\begin{array}{ccccccccc}1 & 2 & 3 & 4 & 5 & 6 & 7 & 8 \\ 13.2 & 30.0 & 5.0 & 10.5 & 14.0 & 10.0 & 7.0 & 10.3=100\end{array}$

The first segment is rather short, bearing three stout setae. The second segment is very large, equivalent in length to that of all other segments combined. This segment bears a number of setae spread all along its length. Third segment is the shortest and characteristically wider in its anterior half. The fourth segment is longer than the third. Both these segments bear three setae each. The next four segments diminish both in length and width to the apex, quite a number of setae being borne on these segments. Antenna (Fig. XIII. 6) is very stoutly built and is equivalent in length to the antennnule in the natural position. They are held at right angles to the main axis of the body. Each antenna consists of four segments. First segment has a deep curve in its distal posterior margin and bears a solitary seta on the opposite margin. The second is the largest segment of the antenna and is barrel like, bearing one seta on its anterior margin at its mid-length. The third segment is the shortest of all and has three setae on its antero-lateral corner. The distal segment bears two claws and four setae; three of the setae are apical and of unequal length, the fourth one is rather small and subapical on the posterior margin. Mandible (Fig. XIII, 7) consists of basal broader blade and a distal tapering lappet. The latter is lined on its both margins with fine spinules. The basal broader part carries a ridge with fine spinules on it on the postero-distal margin. The anterodistal margin bears a similar row of spinules. Maxillule (Fig. XIII, 7 ) is similar to that of the preceding species. Maxilla (Fig. XIII, 8) is rather simple. It is a rectangular appendage with an apical lash which, compared to that of the known species of the genus, is quite short; the lash is provided with stiff hairs on one margin. Maxilliped (Fig. XIII, 9) is very small and consists of two segments. The first segment is larger than the second and has its proximal part expanded inwards. The second segment bears a small spine and two setae both of which are borne at some distance from the apex.

The four pairs of swimming legs (Fig. XIII, 10 \& Fig. XIV, 1, 2 \& 5) are borne by the four prosomal segments. The first three pairs are biramous, the ramus consisting of three segments. The last pair of legs are biramous, too, but the inner ramus consists only of two segments. The first pair of legs are slightly smaller than the following legs. The ornamentation of the swimming legs are as follows :-

\begin{tabular}{|c|c|c|c|c|c|c|c|c|c|c|c|c|c|c|c|c|c|c|}
\hline & \multicolumn{4}{|c|}{ Protopod } & \multicolumn{7}{|c|}{ Endopod } & \multicolumn{7}{|c|}{ Exopod } \\
\hline & 1 & & 2 & & 1 & & 2 & & & 3 & & 1 & & & 2 & & 3 & \\
\hline & $\mathrm{Si}$ & $\mathrm{Se}$ & Si & $\mathrm{Se}$ & Si & Se & $\mathrm{Si}$ & Se & $\mathbf{S i}$ & St & Se & $\mathbf{S i}$ & Se & $\mathrm{Si}$ & $\mathrm{Se}$ & Si & St & Se \\
\hline $\mathbf{P}_{\mathbf{1}}$ & 0 & o & 0 & 1 & 1 & 0 & 1 & 0 & 4 & 1 & I & 0 & I & 1 & I & 4 & I & III \\
\hline $\mathbf{P}_{\mathbf{a}}$ & 0 & 0 & 01 & 0 & 1 & 0 & 2 & 0 & 3 & I & II & 0 & I & 1 & I & 5 & I & III \\
\hline $\mathbf{P}_{3}$ & 0 & 0 & 0) & 0 & 1 & 0 & 2 & 0 & 2 & II & I & 0 & $\mathbf{I}$ & 1 & I & 5 & $\mathbf{I}$ & III \\
\hline P. & 0 & 0 & 0 & 1 & 1 & o & - & . & II & & & 0 & I & 1 & I & 4 & I & III \\
\hline
\end{tabular}




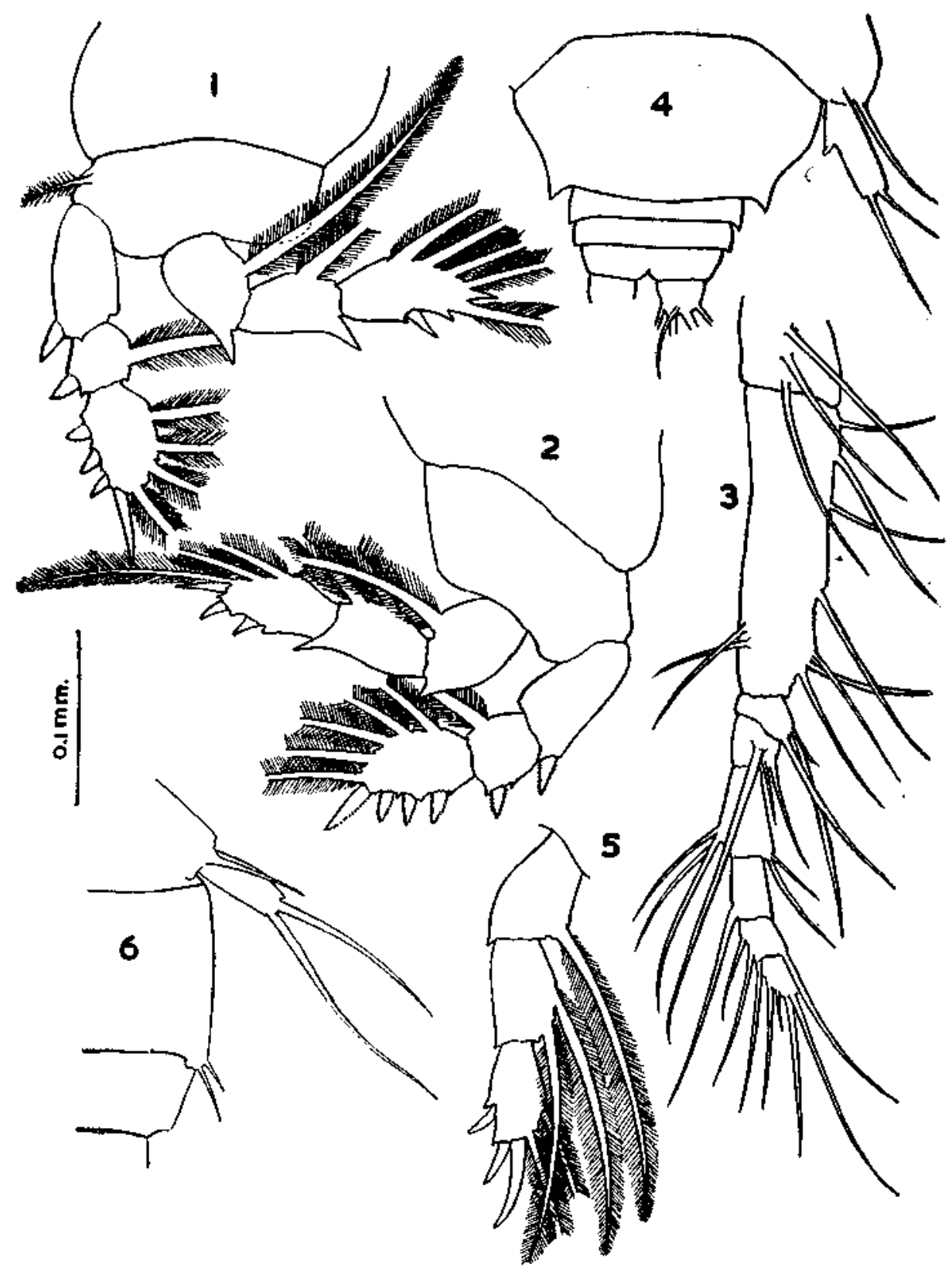

Figure XIV, 1-6. Lichomolgus serratipes sp. nov.

1. Adult, female, first swimming leg. $\quad$ 4. Adult, female, fifth leg with parts of urosome.

2. " " " second swimming leg. $\quad 5$. antennule. Lichomolgus indicus sp. nov.

6. Adult, female, fifth leg with parts of urosome. 
The ffith leg (Fig. XIV, 4) is 2-segmented, but the basal segment is completely confluent with the first urosomal segment. It bears a solitary seta on the distal outer angle. The distal segment is rather rectangular having two setae of unecual length on the terminal margin ; the inner margin of the distal segment is broken at about the midlength by an indentation which projects prominently towards the posterior side. The fifth legs, in their natural position, just reach the posterior margin of the genital segment. The female is $1.5 \mathrm{~mm}$. long.

\section{B. Male}

See Addendum.

\section{Lichomolgus brevifurcaitus sp. nov.}

Material examined: Two female and several male specimens of this species were obtained in the Gulf of Mannar from the starfish washings. The specimens were all in good condition and were pale yellow in colour. The holotype, the allotype and the paratypes are deposited in the Central Marine Fisheries Research Institute and have the registered numbers J. 662/13, J. 663/13 and J. 664/13 respectively.

\section{A. Female}

\section{Description :}

The Body: (Fig. XI, 11) is graceful, rather elongate, with the prosome and urosome merging into each other. The prosome is composed of only four segments, the cephalosome and the first metasomal segments having been fused completely to form a cephalothorax. The latter is the largest of the body segments and constitutes two-fifth of the whole body ; it is also quite wide, more than twice as wide as the last prosomal segment. A semi-spherical rostral prominence is present on the anterior margin. The posterior corners of this segment is smoothly curved. of the remaining three segments the second is the longest and the third the shortest. These segments diminish in width gradually to the posterior side. All segments are provided with lateral expansions. The urosome consists of five segments, the fifth leg-bearing segment, the genital segment and three abdominal segments. The first two are of equal width while the last three decrease in breadth posteriorwards ; in length, however, the three abdominal segments show the reverse situation, namely, the last segment is the longest and the first the shortest. The genital segment is barrel-like and does not become narrowed in the posterior half. The caudal ramus is very short, distinctly wider than long. It is only half as long as the last ibdominal segment. Each furca bears six setae, four of them much smaller than the other two.

The antennule (Fig. XI, 2) is 7 -segmented, segments bearing the following proportionate lengths :--

$\begin{array}{ccccccccc}1 & 2 & 3 & 4 & 5 & 6 & 7 & \\ 15.4 & 33.1 & 8.1 & 18.2 & 10.3 & 7.2 & 7.7 & =100\end{array}$

The second segment is the longest and is half as long as the length of all other segments combined ; the last segment is the shortest and bears a single aesthetask on its apex. All the segments are provided with a number of setae. The antenna 


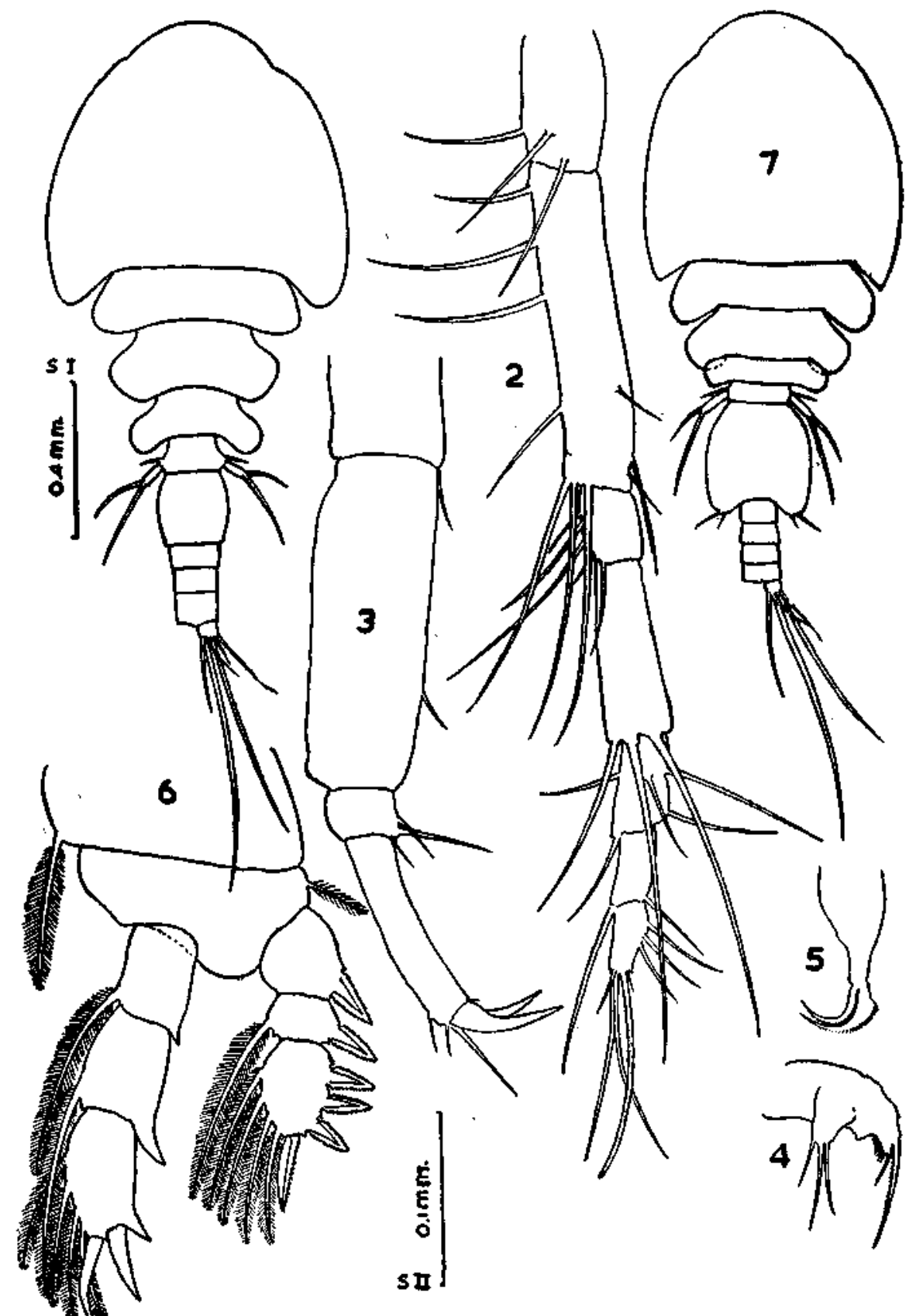

Figure XI, 1-7. Lichomolgus brevifurcatus sp. nov

$$
\begin{aligned}
& \text { 1. Adult, female, dorsal view. } \\
& \text { 2. " " antennule. } \\
& \text { 3. " male, antenna. } \\
& \text { 4. " " mandible and maxillule. } \\
& \text { 5. " " maxilla. } \\
& \text { 6. " " first swimming leg. }
\end{aligned}
$$

(Diagrams 1 and 7 drawn according to scale I and 2.6 to scale II) 
(Fig. XI, 3) is stoutly built, only a little smaller than the antennule and 4-segmented. The first segment bears a solitary seta at its antero-distal corner. The second segment bears a seta on its anterior margin at about two-third the length. The third segment is provided with three setae of unequal length all on the distal anterior margin. There are two short spines and three setae on the last segment, besides a few hairs. Two of the setae are apical and one subapical. The mandible (Fig. XI, 4) is moderately developed with broader basal and narrower distal parts. The former carries a ridge at its distal outer margin and a number of large spinules on its distal inner margin. The apical lash is long and carries spines on the margins. The maxillule (Fig. XI, 4) is normal similar to those described for earlier species. The maxilla (Fig. XI, 5) with none of the spinules of the apical lash particularly strong; the body proper narrower towards the distal part. Maxilliped is quite normal, short and stout, two-articulate, the last segment hearing a spine which is broad at the base.

There are four pairs of swimming legs (Fig. XI, 6 \& Fig. XII, 1, 2 \& 3) ; all are biramous; the rami of the first three pairs of legs as well as the exopod of the fourth leg are 3-segmented, while the endopod of the fourth leg is only 2-segmented. The ornamentation of the swimming legs is as follows :-

\begin{tabular}{|c|c|c|c|c|c|c|c|c|c|c|c|c|c|c|c|c|c|c|}
\hline & \multicolumn{4}{|c|}{ Protopod } & \multicolumn{7}{|c|}{ Endopod } & \multicolumn{7}{|c|}{ Exopod } \\
\hline & & & 2 & & & & & & & 3 & & & & & & & 3 & \\
\hline & $\mathrm{Si}$ & Se & Si & Se & $\mathrm{Si}$ & Se & $\mathbf{S i}$ & Se & $\mathbf{S i}$ & $\mathbf{S t}$ & $\mathrm{Se}$ & $\mathbf{S i}$ & $\mathrm{Se}$ & $\mathbf{S i}$ & Se & $\mathrm{Si}$ & St & $\mathrm{Se}$ \\
\hline $\mathbf{P}_{1}$ & 1 & 0 & 0 & 1 & 1 & 0 & 1 & 0 & 4 & I & I & 0 & .I & 1 & I & 4 & I & III \\
\hline $\mathbf{P}_{\mathbf{g}}$ & 1 & 0 & 0 & 1 & 1 & 0 & 2 & 0 & 3 & III & I & $\mathbf{0}$ & $I$ & 1 & I & 5 & I & III \\
\hline $\mathbf{P}_{3}$ & 1 & 0 & 0 & 1 & 1 & 0 & 2 & 0 & 2 & III & I & 0 & I & 1 & I & 5 & I & III \\
\hline P. & 0 & 0 & 0 & 1 & 1 & $\mathbf{0}$ & & 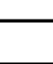 & & & & 0 & I & 1 & I & 5 & I & 【 \\
\hline
\end{tabular}

All the legs are more or less of equal length. In the first three pairs of legs the endopods are distinctly longer than the exopods while in the fourth leg the situation is reverse. The protopod in all cases is very much stumpy and large. Fifth leg consists of two segments. The basal segment, however, merges with the first urosomal segment, and bears a solitary seta at its outer upper angle. The distal segment is rather rectangular with the long axis more than twice as long as its short axis ; it bears two setae terminally and they are of unequal length. The length of the female is $1.6 \mathrm{~mm}$.

\section{B. MALE}

The male (Fig. XI, 7) is much smaller than the female but is more robust in appearance. In the prosome the reduction in breadth from the first to the second segment is gradual while it is rather abrupt in the female. This is because of a proportionate increase in the width of second and third prosomal segments. The urosome is composed of six segments, the fifth leg-bearing segment, the genital segment and four abdominal segments. The first segment is the shortest; in breadth it is only half as wide as the last prosomal segment. The genital segment is quite large and is equivalent in length to that of all other urosomal segments combined; it is 
very much expanded laterally and bears two spines of unequal length on its posterolateral corners. The abdominal segments are more or less of equal dimensions and form a column. The furcal rami are similar to those of the female. The male measures $1.5 \mathrm{~mm}$.

All the appendages are identical with those of the female except the maxilliped which is well developed, subcheliform with a long curved hook ; it probably has a geniculate function. The second segment bears a seta on its inner margin at about its mid-length, and the third segment bears a single seta on its apical margin; a number of stiff hairs, linearly arranged on its long axis, are present on the second segment.

\section{Lichomolgus indicus sp. nov.}

Material examined.-Four female and two male specimens were obtained along with the preceding species from the Gulf of Mannar in July 1960. A single female specimen was later obtained from the sponge washings of the same area. The type specimens, the holotype, allotype and paratypes are deposited in the Central Marine Fisheries Research Institute, Mandapam Camp and have the registered numbers J. $667 / 14, \mathrm{~J} 668 / 14$ and $\mathrm{J} 669 / 14$ respectively.

\section{A. Female}

Description :

This (Fig. XII, 4) is much smaller species than the preceding one. In the pro* some, the cephalosome is separate from the first metasomal segment but the line of demarcation is rather faint. The cephalosome bears a distinct rostral prominence. Both these segments are more or less of equal breadth. The following three prosomal segments diminish in width posteriorwards. In length they are subequal. The urosome consists only of four segments, the pregenital, the genital and two abdominal segments. The first segment is quite normal and bears the fifth pair of legs. The genital segment is partly divided at about its three-fourth length and the portion posterior to the line of division is narrower than that before it. Two spines of unequal length are present at the postero-lateral corners of the proximal division. Of the abdominal segments, the second is larger than the first, but they are both of equal width. Caudal ramus is very short, less than half the length of the last abdominal segment; it is distinctly broader than long; each ramus bears five setae, two of which are fairly long while other three are very small.

Antennule (Fig. XII, 5) is 7-segmented, the relative lengths of the different segments being as follows :

$\begin{array}{ccccccc}1 & 2 & 3 & 4 & 5 & 6 & 7 \\ 14.2 & 32.5 & 6.1 & 15.0 & 13.4 & 9.4 & 9.4\end{array}$

4100

While in the preceding species the terminal segment is the shortest antennular segment, in the present case it is third segment which is the shortest. The relative length of the second segment is similar in both cases. The setation of the different segments also bears certain kinship, especially in the presence of two very long setae on the distal margin of the fourth segment. However, no aesthetask is present on the terminal antennular segment. Antenna (Fig. XIII, 1) is quite normal, 4segmented and having great resemblance to that of the preceding species. Mandible 
and maxillule (Fig. XIII, 6) are normally built and are as shown in the figure. Maxilla (Fig. XII, 7) is stouter than that of the earlier species, apical lash with spinules of uniform size ; the spine at the base strongly built. Maxilliped (Fig. XII, 8) is very small and 2 -segmented ; the first segment bears a few spinules on its midinner margin ; the second segment bears a solitary seta at about its mid-length and a conical, broad-based spine at the apex.

The four pairs of swimming legs (Fig. XII, 9 and XIII, 2, $3 \& 4$ ) are borne by the last four prosomal segments respectively. Both rami are of about equal length in all legs except the fourth where the endopod is shorter because of its two segmented nature. The ornamentation of the swimming legs is as follows :

\begin{tabular}{|c|c|c|c|c|c|c|c|c|c|c|c|c|c|c|c|c|c|c|}
\hline & \multicolumn{4}{|c|}{ Protopod } & \multicolumn{7}{|c|}{ Eindopod } & \multicolumn{7}{|c|}{ Exopod } \\
\hline & & 1 & 2 & & 1 & & 2 & & & 3 & & & & & & & 3 & \\
\hline & Si & $\mathrm{Se}$ & $\mathbf{S i}$ & Se & $\mathbf{S i}$ & Se & $\mathrm{Si}$ & $\mathrm{Se}$ & $\mathrm{Si}$ & St & Se & $\mathrm{Si}$ & Se & $\mathrm{Si}$ & $\mathrm{Se}$ & $\mathrm{Si}$ & St & $\mathrm{Se}$ \\
\hline $\mathbf{P}_{\mathbf{x}}$ & 1 & 0 & 0 & 1 & I & 0 & 1 & 0 & 4 & I & 0 & 1 & I & I & I & 4 & I & III \\
\hline $\mathbf{P}_{2}$ & 1 & 0 & 0 & 1 & 1 & 0 & 2 & 0 & 3 & I & II & 0 & I & 1 & $\mathbf{I}$ & 5 & I & III \\
\hline $\mathbf{P}_{3}$ & 1 & 0 & 0 & 1 & 1 & 0 & 2 & 0 & 2 & I & II & 0 & I & 1 & I & 5 & I & IJI \\
\hline$P_{*}$ & 1 & 0 & 0 & 1 & 1 & 0 & 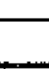 & & II & & & 0 & I & 1 & 1 & 4 & I & II \\
\hline
\end{tabular}

A number of differences can be noticed in the setal arrangement of the swimming legs. of this species and this difference extends to the terminal endopod segments of atl the four pairs of legs and in the terminal exopod segment of the fourth leg. In general the tendency in the present species is to a reduction in the number of spines. The fifth legs (Fig. XIV, 6) are 2-segmented, but, here again, the basal segment merges into the leg-bearing segment ; the terminal segment is a littlc more than twice as long as broad and bears two terminal setae, directed postero-laterally. The size of the female is $1.05 \mathrm{~mm}$.

\section{B. Male}

The male (Fig. XII, 10) exhibits the sexual dimorphism and is smaller than the fernale. The prosome is very similar in both cases. The urosome in male comprises five segments, the fifth leg-bearing segment, the genital and three abdominal segments. The first segment and the abdominal segments are very much identical with those of the female. The genital segment, however, is quite developed, has no trace of any sub-division and is more or less of uniform breadth throughout. Each postero-lateral corners of this segment bears a pair of spines. Caudal ramus is identical to that of the female. The male measures $1.00 \mathrm{~mm}$.

Among the appendages only the maxilliped shows structural modifications from that of the female. While in the latter it is very dwarf and 2-segmented, here it is fairly large and with a long apical hook. The appendage bears great resemblance to that of the preceding species.

Remarks. $\longrightarrow$ The genus Lichomolgus is an extremely vast group of animals, " a lumber-room for those species that do not belong to any of the other genera' of the 


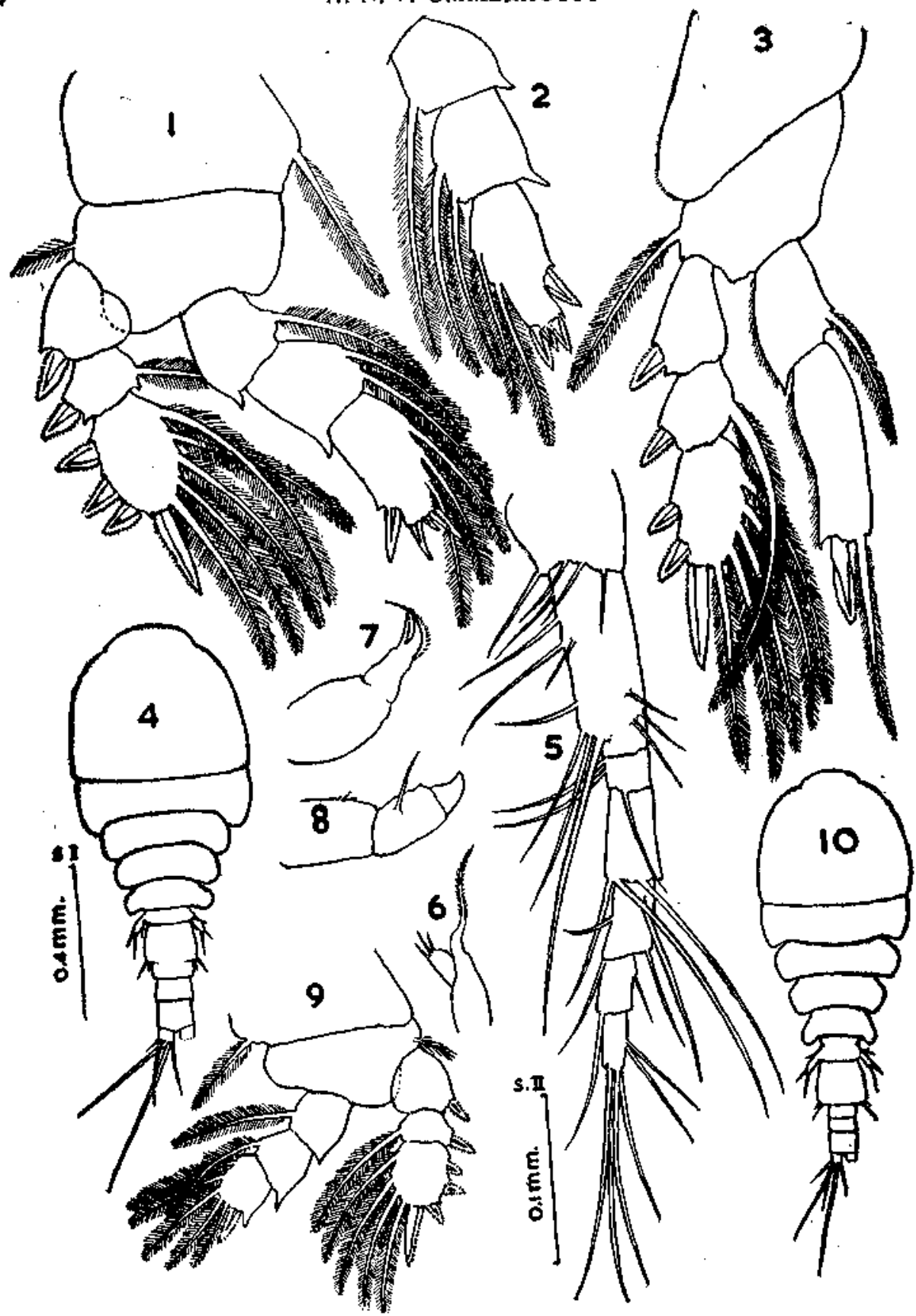

Figure XII, 1-10. Lichomolgus brevifurcata sp. nov,

1. Adult, male, second swimming leg.

2. " " endopod of third swimming leg.

3. " " $"$ fourth swimming leg.

4. Adult, female, dorsal view.

5. " " antennule.

Lichomolgus indicus sp. nov.

| 8. Adult, female, maxilliped.

6. " " mandible and maxillule. 10. " mäle, dorsal viewning leg.

7. " " maxilla.

(Diagrams 4 and 10 are drawn to scale I and others according scale II) 
subfamily Lichomolginae. The difficulty of obtaining large number of representatives, the meagreness of the descriptions of the several species and the in: numerable number of species that have been assigned to this genus from various parts of the world at different times make a comparative study of the known species of this genus extremely delicate. To this must be added the fact that several species have been transferred and retransferred from genus to genus because of the disagreement that exists among the scientists as to the validity or otherwise of some of the genera of the subfamily Lichomolginae.' No attempt is, therefore, made here, to determine the validity or synonymy of any of the species. The four species described in this paper do not correspond exactly to any of the known forms and, therefore, are treated as new.

Lichoomolgus serratipes is very near to $L$. pteroidis Della Valle but differs from, it in several details :

\section{L. pteroidis}

1. Size-not given. (ch. Stock, 1959)

2. The length-width ratio of the first prosomal segment is $40: 60$.

3. The marginal serration of the second prosomal segment is visible from the dorsal side.

4. Antennule 7-Segmented.

5. The terminal segment of the first endopod of male carries a large spinular growth which is half the length of the segment itself.

6. The post-genital segments of urosome are clearly visible from the dorsal side. The middle region of the lateral margins of the male genital segment is smooth.

7. In the female the spiniform projection and the lateral expansion of the fifth leg well beyond the $\frac{3}{4}$ length.

Recently, Stock has described another species, $P$. pterophilus from the Indonesian waters. Unfortunately I have not seen the description of the species.

Both $L$. pteroidis and $L$. serratipes (and probably $L$.pterophilus) are closely allied to the four species of lichomolgids, $L$. venustus, $L$. patulus, $L$. audens and $L$. asaphidis. Humes that have recently been added from Madagascar (Humes, 1958). In all these forms the antennule is 8-segmented, the body, particularly the first prosomal segment, is very much broadened (except in asaphidis), the genital segment in both sexes is very large and there is complete fusion between the cephalosome and the first pedigerous segment. There is great similarity also in the oral appendages and the swimming legs.

L. holothuriae appears to be a true representative of the subgenus Stellicola. This species, together with L. curticaudata (Thompson \& Scott) L. asterinae Bocquet, $L$. frequences, $L$. astropectinis, $L$. luidiae and $L$. lautus Humes \& Cressey constitute a closely related group of species. All are characterised by (a) an 8 -segmented antennule ; (b) a 3-segmented antenna and. (c) the setal formula for the fourth endopod of $0 \mathrm{I}$, II 1 . 
L. holothuriae is quite close to L. curticaudatus and may even be conspecific with it. However, it is treated as a separate species because of the following reasons : (1) There is complete fusion of the cephalosomal segment and the first pedigerous segment in $L$. holothuriae while they are distinctly separate in $L$. curticaudatis. (2) The urosome is less than one-third the length of the prosome in L. curticaudatus; in the present species it is clearly more than one-third the length of the prosome. (3) In holothuriae the genital segment is longer than the next three segments joined together; in curticaudatus it is distinctly shorter. (4) The maxilla is different in the two species.

The nearest relative of L. brevifurcatus is perhaps L. robustus Thomp. \& Scott, but the differences between the two forms are many and are noted below: (1) in $L$. robustus the cephalosome and the first metasomal segment are separate while in $L$. brevifurcatus they are completely fused. (2) In $L$. robustus the genital segment is $1 \frac{1}{2}$ times wider than long; in L. brevifurcafus the breadth and length of the genital segment are the same. (3) A distinct rostral prominence is visible from the dorsal side in the present species, whereas it is not visible in $L$. robustus. (4) Caudal ramus in $L$. robustus is only a little shorter than the last abdominal segment ; it is only less than half the length of the last abdominal segment in L. brevifurcatus. (5) The longest furcal seta in the present form is longer than the urosome while it is less than half the length of the urosome in L. robustus. (6) The last exopod segment of the fourth leg in $\vec{L}$. robustus bears three spines on the outer margin and one spine terminally while in the present case there are only two spines on the outer margin besides the apical spine.

$L$. indicus is quite distinct enough from all other species in the very general appearance and comparatively smaller size. The two-segmented nature of the abdomen brings down its immediate probable relatives to quite a few. The species is easily identified by the combination of the following characters. - (1) Cephalosome and the first metasomal segment separate. (2) The fifth leg-bearing segment is very short, being the shortest of the urosomal segment. (3) The genital segment exhibits a partial division at about three-fourth the length in its distal part ; the posterior division is narrower; at the postero-lateral corner of the latter there is a pair of spines. (4) The genital segment is equivalent in length to that of the two abdominal segments joined together. (6) In the antennule the second segment is the longest and the third the shortest. (7) The setal formula of the swimming legs is peculiar and is given above in the text.

\section{SUMMARY}

Eleven new species of cyclopoid copepods, four belonging to the section Siphonostoma and the rest to the section Poecilostoma are described in detail. Six of the species are represented by both the female and the male sexes while others are known only from the females. The material of the present investigations was collected both from the Gulf of Mannar and the Palk Bay off Mandapam on the southeast coast of India during the months of May, June, July and August, 1960. The collections were made in the inshore waters and the methods of collection are discussed.

The composition of the cephalosomal appendages of the siphonostomatous cyclopoids is briefly considered. The present study shows that there are four pairs of oral appendages, the mandible, the maxillule, the maxilla and the maxilliped besides the preoral antennule and antenna on the cephalosome. 
The following genera are represented in the present collection:

1. Asteropontius Thompson \& Scott.

2. Cryptopontius Giesbrecht.

3. Hemicyclops Boeck.

4. Pseudoanthessitus Canu.

5. Macrochiron (Macrochiron) Brady, Sewell.

6. Lichomolgus Thorell.

A key to the identification of the various known species is provided for the genus, Asteropontitus. In other cases the species described in this paper are diagnosed and a comparison between the forms treated here and the previously known forms is rendered.

\section{ACKNOWLEDGEMENTS}

My grateful thanks are due to Dr. S. Jones, Chief Research Officer for his constant encouragement and guidance during the period of this investigation. I am also thankful to him for supplying me specimens of Lichomolgus serratipes sp. nov. I am much indebted to Dr. S. Krishnaswamy of the Madras University who helped in the Identification of the various species treated in this paper and who very generously placed at my disposal many relevant literature. My sincere thanks are due to Dr. S. Z. Qasim of the Aligarh University for his continued interest in this work and for the many valuable suggestions he kindly gave for the improvements of this paper.

Brady, G. S. 1872. A list of Non-parasitic Copepoda of the North-East Coast of England. Trans, Nat. Hist. Soc. Northumberland, Durham and Newcastle, $I V$.

BOCQuet, C. 1952. Copepodes semi-parasites des Echinodermes de la region de Roscoff. Des. cription de Lichomolgus asterinae n. sp. Bull. Soc. Zool. Fr., 77 : 495-504.

CANU, E* 1888. Les Copepodes marins du Boulonnais; III. Les Hersiliidae, Famille nouvelle du Copepodes commensaux. Bull. Soc. France et Belge, XIX.

-1. 1892. Les Copepodes du Boulonnais. Travaux du Lab, de Zool. Marit. de WimeretaxAmbleteuse, VI.

Emburton, Auce L. 1901. Goidelia japonica-a New Entozoic Copepod from Japan, associated with an Infusiorian (Trichodinal). J. Linn. Soc, London, Zool. XXVII.

Goodna, R. U. 1957. On some Copepoda from Plymouth, mainly associated with invertebrates, including three new species. J, Mar. biol. Ass. U.K., 36, 195-221.

1960. North and South American Copepods of the genus Hemicyclops (Cyclopoida ; Clausiditdae) Proc. U.N. nat. Mus., 112, No. 3434 : 159-195.

GuRNey, R. 1927. Cambridge Expedition to the Suez Canal, 1924 : Report on the Crustacea Copepoda (Littoral and Semi-parasitic) Trans. Zool. Soc. London, XXII, Pt. 4.

Humes, A. G. 1958. Copepodes parasites de mollusques a Madagascar. Memo. de L'Inst. Sct. de Madagascar. Ser. F. Tome II. 285-342.

AND R. F. CRessey, 1958. Copepod parasites of Mollusks in West Africa. Bull. de II.F.A.N. T.XX, ser A, no. $3 ; 921-942$. pl. 1-18. 
Humes, A. G., AND R. F. Cressey. 1958. Four new species of lichomolgid copepods parasitic on West African starfishes. Ibid, no. $2 ; 330-341$, pl. 1-10.

Humes A. G., R. S. Cressey and R. U. Gooding. 1958. A new cyclopoid copepod, Hemicyclops visendus, associated with Upogebia in Madagascar. J. Washington Acad. Sci., 48, (12): 398-405.

KRISHNaswamy, S. 1954. Three semiparasitic copepods from the Madras coast. Rec. Indian Mus., 54, (1 \& 2): 23-27.

Lioht, S. F. and O. Hartman. 1937. A review of the genera Clausidium Kossmann and Hemicyclops Boeck (Copepoda, Cyclopoida), with description of the new species from the NorthEast Pacific. Univ. Calif. Pub. Zool., XLI, 1 : 173-184.

Monod, Th.* 1928. Sur quelques Copepodes parasites de Nudibranches. Bull. Inst. Oceanogr. Monaco, No. 509.

Monop, Th. AND R. Dollfus. 1932. Les Copepodes parasites de Mollusques. Ann. de Paran sitol., $\mathbf{X}(2)$ : 129-204.

Nicholls, A. G. 1944. Littoral copepoda from S. Australia ; (II) Calanoida, Cyclopoida ; Notodelphyoida, Monstrilloida and Caligoida. Rec. S. Austratian Mus., VIII, 1:1-62.

SARS, G. O. 1913-1918. Copepoda Cyclopoida. Crustacea of Norway. VI.

Scorr, A. 1902. On some Red Sea and Indian Ocean Copepoda. Trans. Liverpool Biol. Soc., XVI.

ــ. 1909. The Copepoda of the Siboga Expedition, Pt. I. Free-swimming, Littoral and Semi-parasitic Copepoda. Siboga-Expeditie, XXIX.

-Serban, M. 1956. Pontocyclops bacescui n.g., n.sp., (Crustacea Copepoda), ein neuer Cyclo- pide vom schwarzen Meere. Izdanija (In Russian) 1 : 169-184.

SewelL, R. B. S. 1949. The Littoral and Semi-parasitic Cyclopoida, the Monstrilloida and Notodelphyoida. Scl. Rep. John Murray Exped. Vol. IX, $2: 1-199$.

*Shen, C. J. AND S. O. BaI. 1956. The marine Copepoda from the spawning ground of Pneumatophorus japonicus (Houttuyn) off Chefoo, China. Aeta Zool. Sinica $8: 177-234$.

$\$$ Trock, J. H. 1957. Some notes on the genus Macrochiron Brady, 1872. Ann. Mag. Nat. Hist., $12,10: 378$.

__ 1959. Copepoda associated with Neapolitan Invertebrates. Pubbl. Staz. Zool, Napoll, $31(1): 59-75$.

Thompson, I. C. And A. Scotr. 1903. Report on the Copepoda. Rep, on the Pearl Oyster Fisheries of the Gulf of Mannar. Supp. Rep. VIII, The Roy. Soc. London.

UMmerkutTY, A. N. P. 1960. Studies on Indian Copepods I. : Paralepeopsyllis mannarensis, a new genus and species of Cyclopoid Copepod from the Gulf of Mannar. J. Mar. biol. Assn. India, 2(1): 105-114.

-. 1960a. Studies on Indian Copepods 2 : An account of the morphology and life-history of a harpacticoid copepod Tisbintra jonesl sp. nov, from the Gulf of Mannar. Ibid. $2(2)$.

_-1960b. Studies on Indian Copepods 3: Nearchinotodelphys indicus, a new genus and species of archinotodelphyid Copepod from Indian Seas. Ibid., 2(2).

Wrson, C. B. 1932. The Copepoda of the Woods Hole Region, Massachusetts. Smithsonian Inst. U.S. Nat. Mus, Bull. $158: 1-635$.

Not personally consulted. 


\section{COPEPODS OF THE SOUTH-EAST COAST OF INDIA \\ ADDENDUM}

Lichomolgus serratipes sp. nov.

MALE

Size $-0.76 \mathrm{~mm}$. The male (Fig. 1, b) is only a little more than half the length of the female. The general body shape corresponds to that of the female. The sexual dimorphism is expressed in the structure of the maxilliped and the urosome.

The maxilliped (Fig. 1, d) is very large, the terminal segment carrying an incurved claw which is equivalent to the two segments combined. The second segment carries. also two setae, one at about the mid-length and the other near the base of the claw. There is a row of spinules along two-third the length of this segment. An elevated ridge is present on the distal area, in continuation with this row of spinules.

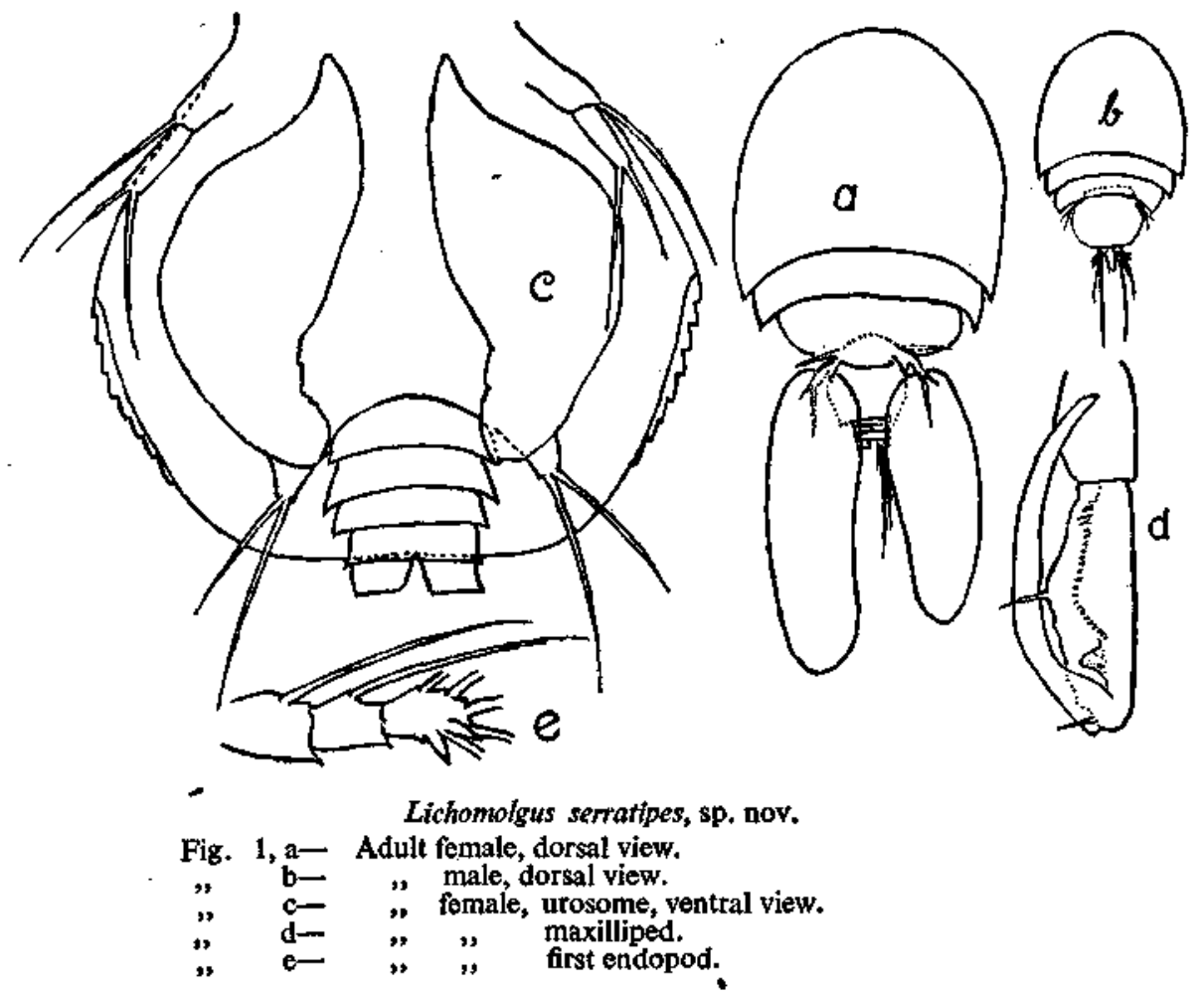

The urosome is 6-segmented, consisting of the fifth-leg bearing segment, the genital segment and four abdominal segments. All segments are very short and crowded together except the genital segment which is exceedingly large and grows both posteriorwards and sidewards, covering most of the abdominal segments. The caudal rami are, however, visible from the dorsal side.

The fifth leg is rectangular, without any lateral expansion or spinular growth. The basal segment, as in the female, is confluent with the first urosomal segment and carries one seta. The distal segment carries two apical setae. All other structures, including the terminal segment of the first endopod (Fig. 1, e) are similar to those of the female. 